\title{
Chronic Stress-Induced Alterations of Dendritic Spine Subtypes Predict Functional Decrements in an Hypothalamo-Pituitary-Adrenal-Inhibitory Prefrontal Circuit
}

\author{
Jason J. Radley, Rachel M. Anderson, Bradley A. Hamilton, Jennifer A. Alcock, and Sara A. Romig-Martin \\ Psychology Department and Neuroscience Program, University of Iowa, Iowa City, Iowa 52242
}

Activation of the hypothalamo-pituitary-adrenal (HPA) axis plays a vital role in promoting adaptation during acute stress, but adverse effects of chronic stress may result from overactivity of this system. Recent evidence highlights a subdivision of GABAergic neurons within anterior bed nuclei of the stria terminalis (aBST) that integrates and relays inhibitory influences to HPA-effector neurons in paraventricular hypothalamus during acute stress, notably from medial prefrontal [prelimbic (PL)] and hippocampal [ventral subiculum (vSUB)] cortical fields. Here we localize the site and candidate mechanism of neuroplasticity within upstream regions of this inhibitory network after chronic variable stress (CVS). Rats bearing retrograde tracer injections in aBST underwent CVS for $14 \mathrm{~d}$. Retrogradely labeled and unlabeled neurons in vSUB and PL were selected for intracellular dye filling, followed by three-dimensional imaging and analysis of dendritic arborization and spine morphometry. Whereas PL neurons displayed decreases in dendritic branching and spine density after CVS, aBST-projecting cells showed a selective loss of mature mushroom-shaped spines. In a follow-up experiment, CVStreated and control rats were exposed to a novel restraint challenge for assay of HPA activation and engagement of aBST-projecting cortical regions. CVS animals showed enhanced HPA output and decreased Fos activation in aBST-projecting PL neurons compared with acutely stressed controls. In contrast, vSUB failed to show any significant differences in structural plasticity or functional activation patterns after CVS. These findings define a mechanism whereby synaptic destabilization in the PL $\rightarrow$ aBST pathway may dampen its ability to impart inhibitory control over the HPA axis after chronic stress exposure.

\section{Introduction}

The neural circuitry underlying control of adaptive responses to acute stress involves the integration of various excitatory and inhibitory signals that are ultimately conveyed to the paraventricular hypothalamus (PVH) for hypothalamo-pituitary-adrenal (HPA) axis activation. The HPA axis is vital for adaptation to acute emergencies, delivering metabolic resources to requisite target tissues and inhibiting nonessential anabolic processes. Nevertheless, adverse effects of chronic stress and stress-related disorders are understood to result, not from failure of, but rather from overactivity of this system (Sapolsky et al., 1986; Conrad, 2008).

During the past few decades, extensive functional neuroanatomical evidence has shown acute emotional stress-induced HPA activation to be modulated by a network of limbic forebrain cell groups, including medial prefrontal cortex (mPFC), hippocam-

Received Jan. 21, 2013; revised July 23, 2013; accepted July 30, 2013.

Author contributions: J.J.R. designed research; J.J.R., R.M.A., B.A.H., J.A.A., and S.A.R.-M. performed research; J.J.R. and R.M.A. analyzed data; J.J.R. wrote the paper.

This work was supported by National Institutes of Health Grant MH-095972 (J.J.R.). We thank Shelley Plattner for technical assistance, and Donna Farley for assistance with radioimmunoassays.

Correspondence should be addressed to Dr. Jason Radley, Department of Psychology, University of lowa, E232 Seashore Hall, lowa City, IA 52242. E-mail: Jason-radley@uiowa.edu.

DOI:10.1523/JNEUROSCI.0287-13.2013

Copyright $\odot 2013$ the authors $\quad 0270-6474 / 13 / 3314379-13 \$ 15.00 / 0$ pal formation (HF), septum, and paraventricular thalamus (Feldman and Conforti, 1980; Diorio et al., 1993; Herman et al., 1995b; Jaferi and Bhatnagar, 2006). Thus, HPA sensitization after chronic variable stress (CVS) exposure (14 d exposure to two different stressors daily at unpredictable times; Herman et al., 1995a; Willner, 1997; Grippo et al., 2002) may result from a diminution of inhibitory control otherwise imparted by this network under acute conditions. However, unraveling these mechanisms has been hindered by the fact that the limbic forebrain pathways to $\mathrm{PVH}$ are indirect, instead innervating a number of $\mathrm{PVH}$ projecting intermediary cell groups. Recent evidence highlights a subpopulation of GABAergic neurons in the anterior division of the bed nuclei of the stria terminalis (aBST) that integrates and relays information from $\mathrm{mPFC}$ [notably, from the prelimbic area (PL)] and HF [via outputs from ventral subiculum (vSUB)] directly to $\mathrm{PVH}$, thereby inhibiting HPA activation during acute emotional stress (Radley et al., 2009; Radley and Sawchenko, 2011). These studies raise the possibility that regressive structural alterations in HF and mPFC that result from chronic stress exposure (Watanabe et al., 1992; Radley et al., 2006b; Liu and Aghajanian, 2008; Hajszan et al., 2009) may shift the balance of an HPA-inhibitory network to a state of hyperactivity.

To examine this issue, pyramidal neurons in rat PL and vSUB regions implicated in HPA-inhibitory circuitry were retrogradely 
labeled by tracer injections in aBST, followed by CVS exposure. Retrogradely labeled and unlabeled neurons were filled with Lucifer yellow (LY) in CVS and control groups for analysis of dendritic arborization patterns and spine morphometry. Whereas all analyzed PL neurons displayed regressive changes in dendritic morphology and spine density after CVS, aBST-projecting cells showed selective decreases in mushroom-shaped spines. Because these spines represent mature, stable excitatory synapses (Harris and Stevens, 1989; Matsuzaki et al., 2001; Yasumatsu et al., 2008), we next queried whether their depletion in aBST-projecting PL neurons would be paralleled by decreases in functional activation of this circuit and HPA sensitization. CVS-treated and control rats were exposed to a novel restraint challenge for assay of HPA activation and engagement of aBST-projecting cortical regions. CVS animals showed enhanced HPA output and concurrent decreases in Fos protein expression in aBST-projecting PL neurons compared with acutely stressed animals. In contrast, CVS failed to produce any significant differences in structural plasticity or activational patterns in vSUB.

\section{Materials and Methods}

\section{Animals and treatments}

Adult male Sprague Dawley albino rats were maintained under standard laboratory conditions and used in all experiments. All experimental protocols were approved by the Institutional Animal Care and Use Committee of the University of Iowa. CVS involved daily exposure to either two brief or one sustained stressor over $14 \mathrm{~d}$, in semirandomized order, at unpredictable times of day (Herman et al., 1995a; Willner, 1997). Brief stressors included open-field exposure (10 min), shaker stress (30 min on an orbital shaker at $100 \mathrm{rpm})$, tail suspension (10 min), forced swim (10 min in room temperature water), and cold exposure $\left(1 \mathrm{~h}\right.$ at $\left.4-7^{\circ} \mathrm{C}\right)$. Sustained stressors included overnight (i.e., 12-16 h) exposure of rats to wet bedding, overcrowding, or isolation. Controls were handled comparably but were not subjected to any of the stress regimens. On the morning of day 15, animals were perfused and brain tissue was harvested for histology.

\section{Surgeries}

Animals received unilateral pressure injections of $2 \%$ fast blue (FB; Polysciences) in volumes of $250 \mathrm{nl}$ (Bentivoglio et al., 1980) in aBST (anteroposterior, $-0.10 \mathrm{~mm}$; mediolateral, $+1.20 \mathrm{~mm}$; dorsoventral, -7.40 $\mathrm{mm}$ from dura) to retrogradely label neurons in PL and vSUB. These stereotaxic coordinates correspond to the region of aBST (i.e., dorsomedial, fusiform, and subcommissural subdivisions of Dong et al., 2001) shown to contain GABAergic relays between upstream limbic cortical and downstream effector neurons in PVH (Radley et al., 2009; Radley and Sawchenko, 2011). Tracer placement, size, and the quality of retrograde labeling were verified by comparison with previous experiments using iontophoretic injections into the same region of aBST and through analysis of convergent aBST innervation patterns in animals bearing dual PL and vSUB anterograde tracer deposits (Radley and Sawchenko, 2011).

Experiment 1: fluorescent dye-filling and morphometric analyses Histology and tissue processing. After a $7 \mathrm{~d}$ recovery period after tracer injections of FB in aBST, groups of rats were subjected to CVS for $14 \mathrm{~d}$. On day 15 , animals were anesthetized with chloral hydrate $(350 \mathrm{mg} / \mathrm{kg}$, i.p.) and perfused via the ascending aorta with $100 \mathrm{ml}$ of $1 \%$ paraformaldehyde and $0.125 \%$ glutaraldehyde in $0.1 \mathrm{~m} \mathrm{PBS}, \mathrm{pH} 7.4$, followed by 500 $\mathrm{ml}$ of $4 \%$ paraformaldehyde and $0.125 \%$ glutaraldehyde in $0.1 \mathrm{M} \mathrm{PBS}, \mathrm{pH}$ 7.4 , at a flow rate of $55 \mathrm{ml} / \mathrm{min}$. The descending aorta was clamped to limit the flow of fixative to the head and upper extremities and to prevent fixation of the adrenal glands. Immediately after perfusions, the adrenal glands were extracted and weighed, and brains were removed and postfixed for 3-4 h. After postfixation, brains were trisected into three blocks containing the rostrocaudal extent of $\mathrm{mPFC}$, aBST, and HF. Blocks containing $\mathrm{MPFC}$ and HF were stored in $0.1 \mathrm{M}$ PBS until being sectioned later that day, and aBST blocks were cryoprotected in $20 \%$ sucrose in $0.1 \mathrm{M}$
PBS overnight at $4^{\circ} \mathrm{C}$. For cell loading, tissue blocks containing mPFC and HF were sectioned coronally using an oscillating tissue slicer (VT-1000S; Leica) into $250-\mu \mathrm{m}$-thick slabs throughout the rostrocaudal extent of each region and were stored in $0.1 \mathrm{M} \mathrm{PBS}$ at $4^{\circ} \mathrm{C}$ until the time of cell loading. Thirty-micrometer-thick coronal sections encompassing the basal forebrain and hypothalamus were collected into five one-in-five series from the remaining block using a freezing microtome (SM-1000R; Leica) and were stored in cryoprotectant solution at $20^{\circ} \mathrm{C}$ until processing.

Intracellular dye injections. The procedure for iontophoretic intracellular dye injections described is based on previous reports (Radley et al., 2004, b, 2008). Coronal sections of $250 \mu \mathrm{m}$ thickness were collected for the dye-injection procedure, mounted on nitrocellulose filter paper, submerged in a tissue culture dish containing $0.1 \mathrm{M}$ PBS, and viewed under fluorescence using a fixed-stage microscope (DM5500; Leica). Injections of 5\% LY (Invitrogen) were made by iontophoresis through micropipettes (1-2 $\mu \mathrm{m}$ inner diameter) under a direct current of $1-6 \mathrm{nA}$ for $5-10$ min. Retrogradely labeled and unlabeled neurons in layer $2 / 3$ of PL and stratum pyramidale of vSUB were selected for the LY injection. Accurate targeting of neurons in the correct structures and laminae were based on knowledge of labeling patterns in PL and vSUB after retrograde tracer injections in aBST (Radley and Sawchenko, 2011) and cytoarchitectonic features of the subfields of interest (Krettek and Price, 1977; Swanson and Cowan, 1977; Vogt and Peters, 1981). The general technique for cell filling involved carefully observing the diffusion of LY from the advancing micropipette tip under $40 \times$ magnification; LY diffuses amorphously until hitting a dendritic process or cell body, whereby the dye becomes restricted intracellularly. After several neurons were filled, tissue sections were mounted onto glass slides and coverslipped in Vectastain (Vector Laboratories).

Neuronal and dendritic reconstructions. Neuronal reconstructions and data analyses were performed by an experimenter unaware of the treatment condition for each animal. Pyramidal neuron dendritic arbors were reconstructed in three-dimensions using a computer-assisted morphometry system consisting of a Leica DM4000R equipped with an Applied Scientific Instrumentation MS-2000 XYZ computer-controlled motorized stage, a QImaging Blue digital camera, a Gateway computer, and morphometry software (MBF Biosciences). Neurons were visualized, and the dendritic tree was reconstructed using a Leica Apochromat $40 \times$ objective with a numerical aperture (NA) of 1.4 and Neurolucida software (MBF Biosciences).

To be considered for analysis, neurons had to exhibit complete filling of the dendritic tree, as evidenced by well-defined endings. A series of strict criteria was used for inclusion of pyramidal neuron apical and basal dendrites for morphologic analysis (Radley et al., 2004, 2005). For apical dendrites, the fact that the primary shaft generally coursed parallel or gently downward from the top surface of the section optimized the probability for retaining complete dendritic arbors (otherwise, sections containing apical dendrites truncated by the upper sectioning plane were inverted). However, because the dye-filling procedure was performed in sections of $250 \mu \mathrm{m}$ depth, it was virtually impossible to retain an entirely intact apical dendritic arbor with no truncations. Thus, apical dendrites included for analyses retained intact secondary and tertiary branches, and truncations were permitted only in collateral branches that appeared to be nearing the point of termination or unlikely to make any additional branchings. For basal dendrites, it was common to retain an average of one to three entirely intact arbors for a given LY-filled neuron; therefore, analyses of only intact branches were performed for this category.

Confocal laser-scanning microscopy. Two-dimensional renderings for each neuron were obtained using Neurolucida software, and a radial distance of $150 \mu \mathrm{m}$ from the soma was selected as a boundary delineating proximal and distal portions of the dendritic tree. Within these regions, one to two branches were randomly selected for each neuron for an average of three segments per neuron and five neurons per region for each animal. The following criteria, based on previous reports (Radley et al., 2006b, 2008), were adopted for the selection of dendritic segments for confocal imaging: dendrites must have (1) possessed a diameter of $<3$ $\mu \mathrm{m}$ because larger diameter dendrites in PL pyramidal neurons exhibit greater variability in spine density values, (2) resided within a depth of 70 
$\mu \mathrm{m}$ from the top surface of the section, because of the limited working distance of the optical system, (3) been either parallel to or course gently relative to the coronal surface of the section to minimize $z$-axis distortion and facilitate the unambiguous identification of spines, and (4) had no overlap with other branches that would obscure visualization of spines. $z$-Stacks for segments that met these criteria were collected on a Leica SP5 confocal laser-scanning microscope equipped with an argon laser and a $100 \times, 1.4$ NA oil-immersion objective, using voxel dimensions of $0.1 \times$ $0.1 \times 0.1 \mu \mathrm{m}^{3}$. Settings for pinhole size ( 1 airy disc), gain, and offset were optimized initially and then held constant throughout the study to ensure that all images were digitized under similar illumination conditions at a resolution of $512 \times 512$ pixels. With these settings, dendritic segments ranged 52-59 $\mu \mathrm{m}$ in length. All confocal stacks included at least 1 $\mu \mathrm{m}$ above and below the identified dendritic segment. For presentation, composites from deconvolved optical stacks were exported first to NIH ImageJ for adjustments to optimize contrast and brightness and then to Canvas (version 10; Deneba Systems) for assembly and labeling.

Dendritic spine analyses. Images were deconvolved with AutoDeblur (Media Cybernetics), and three-dimensional (3D) analyses were performed using the semiautomated software NeuronStudio (http:// research.mssm.edu/cnic/tools-ns.html) (Rodriguez et al., 2003, 2006; Radley et al., 2008) to characterize dendritic length, spine density, and morphometric features (i.e., head/neck diameter, length) for each dendritic spine. Deconvolution improves both the axial and lateral resolution of $3 \mathrm{D}$ images and reduces the smearing of the image in the $z$-axis. NeuronStudio also classifies dendritic spines into categories (thin, mushroom, stubby) based on user-defined parameters. Spines were classified as thin or mushroom if the head/neck diameter ratio was $>1.1: 1$. Within this subdivision, spines with a head diameter $>0.4 \mu \mathrm{m}$ were classified as mushroom or otherwise classified as thin. Spines with head/neck diameter ratios $<1.1: 1$ were also classified as thin if the ratio of spine length/ neck diameter was $>2.5$; otherwise, they were classified as stubby. Filopodial spines, having a long and thin shape with no enlargement at the distal tip, were very seldom observed and classified herein as thin. To ensure that NeuronStudio appropriately classified dendritic spines, each $z$-stack was scanned manually by an observer and reclassifications were made as necessary. In this study, a total of 373 dendritic segments were analyzed for spine density and morphometric analyses (198 dendritic segments for PL, 65-70 segments in each of four groups; 175 dendritic segments for vSUB, 55-60 segments in each of four groups). Overall, $\sim 35,000$ PL and $\sim 28,000$ vSUB dendritic spines were analyzed in this study.

Experiment 2: engagement of HPA-inhibitory circuitry after CVS Rats received tracer injections of FB in aBST $7 \mathrm{~d}$ before the $14 \mathrm{~d}$ CVS regimen. Controls were handled comparably but were not restrained. On day 15 , animals were subjected to $30 \mathrm{~min}$ of restraint (i.e., acute restraint vs CVS plus restraint) and remained in their home cages during restraint and until the prescribed time of perfusion for histology, $2 \mathrm{~h}$ after the termination of restraint. A separate group of handled, unstressed controls was included in these experiments to assess the effects of these stress paradigms relative to baseline indices. Rats were anesthetized with chloral hydrate $(350 \mathrm{mg} / \mathrm{kg}$, i.p. $)$ and perfused via the ascending aorta with $100 \mathrm{ml}$ of $0.9 \%$ saline, followed by $900 \mathrm{ml}$ of ice-cold $4 \%$ paraformaldehyde in $0.1 \mathrm{~m}$ borate buffer, $\mathrm{pH} 9.5$, at a flow rate of $55 \mathrm{ml} / \mathrm{min}$. The brains were removed, postfixed for $3 \mathrm{~h}$, and cryoprotected in $20 \%$ sucrose in 0.1 $\mathrm{M}$ phosphate buffer overnight at $4^{\circ} \mathrm{C}$. Five one-in-five series of $30-\mu \mathrm{m}-$ thick frozen coronal sections through the entire brain were cut and collected in cryoprotectant solution and stored at $-20^{\circ} \mathrm{C}$ until processing.

Immunohistochemistry. Localization of Fos protein was performed on free-floating sections by using an avidin-biotin peroxidase protocol (Sawchenko et al., 1990). Fos immunolocalization was performed using a primary antiserum raised against a fragment of rat Fos protein (residues 4-17; Ab-2; Millipore). Endogenous peroxidase was neutralized by treating tissue for $10 \mathrm{~min}$ with $0.3 \%$ hydrogen peroxide, and sections were incubated with primary antiserum at $4^{\circ} \mathrm{C}$ for $48 \mathrm{~h}$ in PBS containing $0.3 \%$ Triton X-100 and 3\% blocking serum. The primary antiserum was localized using Vectastain Elite (Vector Laboratories) reagents, and the reaction product was developed using a nickel-enhanced glucose oxidase method (Shu et al., 1988). Dual immunoperoxidase labeling for Fos and FB immunoreactivity was performed by sequentially localizing the antiserum against Fos using a nickel-enhanced diaminobenzidine method (black nuclear reaction product), as above, followed by an FB antiserum (Chang et al., 1990), without nickel enhancement (brown cytoplasmic product). We have previously verified the specificity of the Fos antiserum by comparison with c-fos mRNA over several different challenge conditions (data not shown).

Hybridization histochemistry. Techniques for probe synthesis, hybridization, and autoradiographic localization of mRNA signal were adapted from Simmons et al. (1989). In situ hybridization was performed using ${ }^{35}$ S-labeled sense (control) and antisense cRNA probes labeled to similar specific activities encoding corticotropin-releasing factor (CRF) mRNA (1.2 kb; Dr. V. Viau, University of British Columbia, Vancouver, British Columbia, Canada). Sections were mounted onto poly-- ${ }_{-}$-lysine-coated slides and dried under vacuum overnight. They were treated with $10 \%$ paraformaldehyde for $30 \mathrm{~min}$ at room temperature, digested with proteinase $\mathrm{K}(10 \mu \mathrm{g} / \mathrm{ml})$ for $15 \mathrm{~min}$ at $37^{\circ} \mathrm{C}$, and acetylated for $10 \mathrm{~min}$. Probes were labeled to specific activities of $1-3 \times 10^{9} \mathrm{dpm} / \mu \mathrm{g}$ and applied to the slides at concentrations of $\sim 10^{7} \mathrm{cpm} / \mathrm{ml}$ overnight at $56^{\circ} \mathrm{C}$ in a solution containing $50 \%$ formamide, $0.3 \mathrm{M} \mathrm{NaCl}, 10 \mathrm{~mm}$ Tris, $1 \mathrm{~mm}$ EDTA, $0.05 \%$ tRNA, 10 mm dithiothreitol, $1 \times$ Denhardt's solution, and $10 \%$ dextran sulfate, after which they were treated with $20 \mu \mathrm{g} / \mathrm{ml} \mathrm{ribo-}$ nuclease A for $30 \mathrm{~min}$ at $37^{\circ} \mathrm{C}$ and washed in $15 \mathrm{~mm} \mathrm{NaCl} / 1.5 \mathrm{~mm}$ sodium citrate with $50 \%$ formamide at $70^{\circ} \mathrm{C}$. Slides were then dehydrated and exposed to x-ray films (Kodak Biomax MR; Eastman Kodak) for $18 \mathrm{~h}$. They were then coated with Kodak NTB-2 liquid emulsion and exposed at $4^{\circ} \mathrm{C}$ for $10-14 \mathrm{~d}$, as determined by the strength of signal on film. Finally, slides were developed with Kodak D-19, fixed with Kodak rapid fixer, and lightly counterstained with thionin.

Functional anatomical analyses. Stereological methods were used to quantify the number of Fos-immunoreactive neurons using the aforementioned computer-assisted morphometry system and StereoInvestigator software (MBF Biosciences). For each analysis, boundaries defining the regions of interest were drawn at $10 \times$ using an adjacent series of Nissl-stained sections. Analyses of Fos-immunoreactive cells were performed on every fifth section, avoiding cells in the outermost plane of focus. Similarly, stereologic approaches were implemented for analysis of dual immunolocalization for Fos and tracer, although here the Foslabeled component of dual-labeled neurons was used as the criterion for counting, to uphold the requirement that the size of the object quantified be small compared with the section thickness. Counts were then multiplied by five to estimate the total number of labeled neurons within PL or vSUB. To probe for possible treatment effects of CVS on volume, 3D estimates from cross-sectional area measurements were obtained using the Cavalieri method, but no effects were observed.

Semiquantitative densitometric analyses of relative levels of CRF mRNA were performed on emulsion-coated slides using NIH ImageJ software, and optical densities of hybridization signals were determined under dark-field illumination at $10 \times$ magnification. The hypophysiotropic region of the PVH (i.e., dorsal medial parvicellular subdivision) was defined from Nissl staining pattern (Swanson and Kuypers, 1980) and aligned with corresponding dark-field images of hybridized sections by redirected sampling. Background-corrected optical density readings were taken from sections at $150 \mu \mathrm{m}$ intervals, and average values were determined through the extent of cell groups for each animal. Images for densitometry were collected using a QImaging EXi Blue camera and were exported into Canvas (version 10) for assembly and labeling.

\section{Experiment 3: hormone assays}

For the assessment of CVS effects on adrenocortical output, plasma corticosterone was repeatedly sampled from CVS and previously unstressed controls in response to a novel $30 \mathrm{~min}$ restraint challenge. Animals subjected to the CVS regimen were implanted with indwelling jugular catheters on day 13 of CVS, and previously unstressed animals were catheterized $2 \mathrm{~d}$ before their only acute restraint stress episode. The procedures for implanting catheters have been described previously (Ericsson et al., 1994; Radley et al., 2006a). On the morning of day 15, $250 \mu \mathrm{l}$ blood samples were taken before restraint stress to estimate basal corti- 
costerone levels, and additional samples were collected at $0,30,60,90$, and $120 \mathrm{~min}$ after the termination of restraint. Samples were collected into chilled EDTA-containing tubes and centrifuged, and then plasma supernatant was stored at $-20^{\circ} \mathrm{C}$ until the assay was performed. Plasma corticosterone was measured without extraction, using an antiserum raised in rabbits against a corticosterone-BSA conjugate and $\left[{ }^{125} \mathrm{I}\right]$ corticosterone-BSA as tracer (MP Biomedicals). The sensitivity of the assay was $0.8 \mu \mathrm{g} / \mathrm{dl}$; intra-assay and interassay coefficients of variation were 5 and $10 \%$, respectively.

\section{Statistics}

Group data for the morphometric analyses were obtained by averaging values from each animal (average of five neurons per region, five animals per group) in retrogradely labeled $\left(\mathrm{FB}^{+}\right)$and unlabeled $\left(\mathrm{FB}^{-}\right)$neurons from PL and vSUB in unstressed control and CVS animals. Inclusion for analysis was contingent on appropriate centering of tracer injections within aBST. Thus, neurons with an observed absence of retrograde transport, compared with neighboring $\mathrm{FB}^{+}$neurons, were selected as $\mathrm{FB}^{-}$neurons. Preliminary comparisons of dendritic arbor and spine indices between $\mathrm{FB}^{+}$and $\mathrm{FB}^{-}$neurons from $\mathrm{PL}$ and vSUB of unstressed control animals failed to reveal any differences, and without any a priori reason to treat these subpopulations separately, they were combined into one $\mathrm{FB}^{+/-}$group for subsequent statistical analyses. In controls, five rats were used in the analysis, with an average of five neurons per region for each animal. For the CVS group, a total of eight rats were used: three animals containing complete sets of $\mathrm{FB}^{+}$neurons, three cases containing sets of $\mathrm{FB}^{-}$neurons, and two cases that contained complete sets each of $\mathrm{FB}^{+}$and $\mathrm{FB}^{-}$cells for each region.

The effects on overall dendritic length, number of branch endings, dendritic spine densities, immunolocalization data, and optical density measurements from hybridization histochemistry were compared using a one-way ANOVA for three groups: (1) control ( $n=5$; retrogradely labeled and/or unlabeled neurons); (2) CVS, aBST-projecting ( $n=5$; $\mathrm{CVS}^{+}$); and (3) CVS, unlabeled ( $n=5$; CVS). Post hoc comparisons were made using a Bonferroni's correction, with significance set at $p<0.05$, and data are expressed as mean \pm SEM. Group data from the hormone assays ( $n=5$ per group) were compared with a mixed-design analysis of variance with one between-group (acute restraint, CVS plus restraint) and one within-group (time) variable, followed by individual pairwise comparisons as above. Data are expressed as the mean \pm SEM.

\section{Results}

\section{Comparison of CVS model to previous work}

CVS and analogous methods (such as chronic unpredictable stress, chronic mild stress, and chronic intermittent stress) are known to produce a constellation of physiological, endocrine, and behavioral changes similar to stress-related psychiatric illnesses in humans (Ottenweller et al., 1989; Papp et al., 1991; Herman et al., 1995a; Willner, 1997; Grippo et al., 2003). Thus, for each experiment, we assayed adrenal hypertrophy and decreases in body weight gain to verify effects of chronic stress. CVS produced consistent and reliable decrements in the percentage of gain in body weight (control, $21.0 \pm 2.7 \%$; CVS, $8.7 \pm 1.8 \%$ ) over the $14 \mathrm{~d}$ stress epoch $\left(t_{(12)}=3.87, p<0.05\right)$ and a significant increase in adrenal weight (grams) by percentage of body weight (kilograms) (control, $0.144 \pm .015 \%$; CVS, $0.201 \pm 0.015 \%$; $\left.t_{(12)}=2.70, p<0.05\right)$ compared with unstressed control animals.

\section{Tracer placements in aBST and limbic cortical retrograde labeling patterns}

An increasing amount of evidence supports a role for aBST as a clearinghouse for limbic forebrain influences over the HPA axis response to emotionally stressful experiences. Within this complex and heterogeneous structure, circumscribed elements within the aBST (dorsomedial, fusiform, and subcommissural subdivisions) house GABAergic neurons that receive, integrate, and relay inputs from PL and vSUB to PVH to inhibit
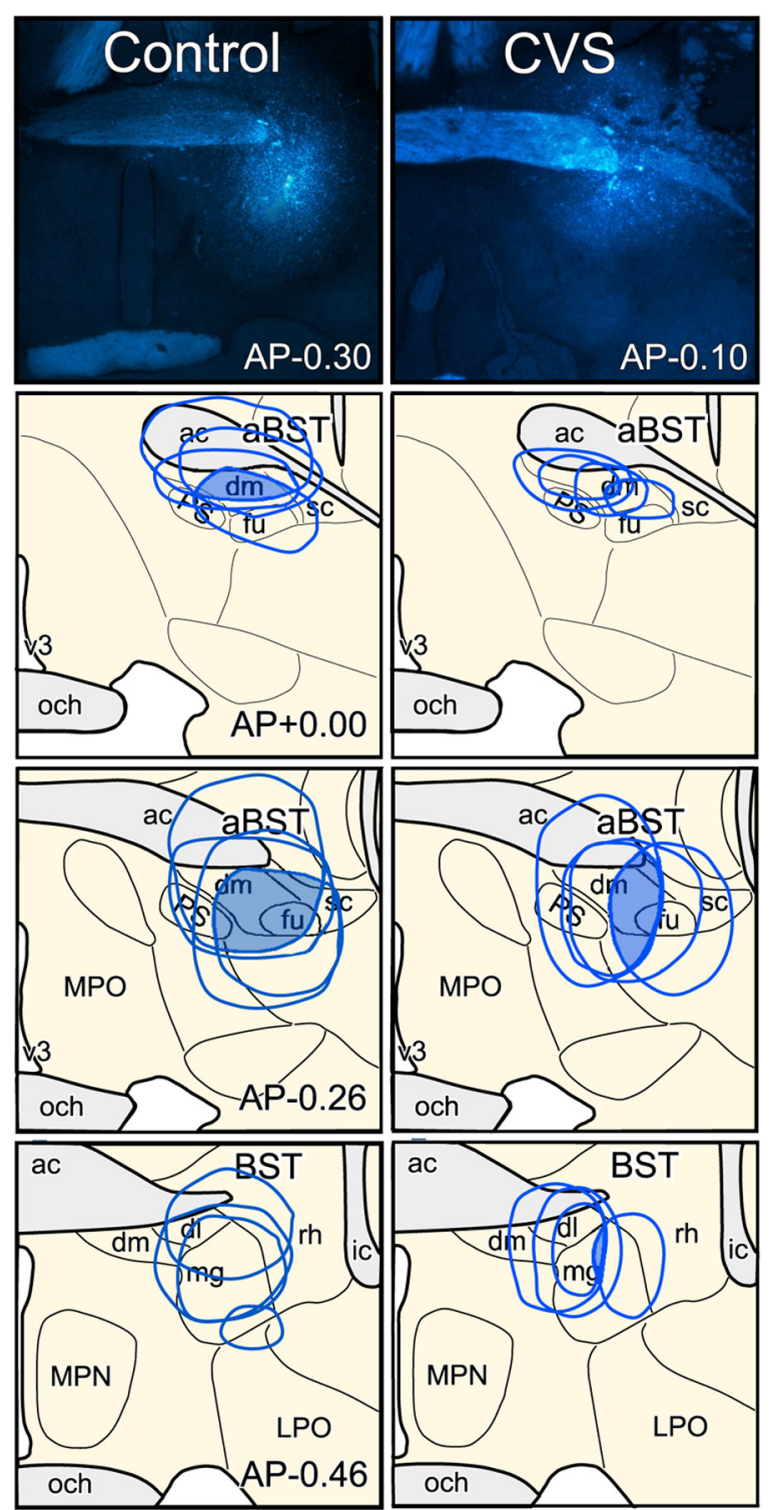

Figure 1. Reconstructions of FB tracer injection placements in aBST in control and CVS rats (left and right columns, respectively). Epifluorescence photomicrographs (top row) depict examples of FB tracer deposits. The shaded regions in the diagrams (below) indicate areas of overlap common to all tracer injections and their approximate extent of diffusion into adjacentlying structures. In the diagrams, four representative examples are shown from each treatment group. ac, Anterior commissure; AP, anteroposterior; dl, dorsolateral subdivision of aBST; dm, dorsomedial subdivision of aBST; fu, fusiform subdivision of aBST; ic, internal capsule; LPO, lateral preoptic area; mg, magnocellular subdivision of posterior BST (pBST); MPN, median preoptic nucleus; MPO, medial preoptic area; och, optic chiasm; PS, parastrial nucleus; rh, rhomboid subdivision of pBST; v3, third ventricle.

acute stress-induced HPA activation (Radley et al., 2009; Radley and Sawchenko, 2011). To examine the effects of CVS on structural plasticity in retrogradely labeled upstream components of this HPA-inhibitory network, tracer injections of FB were made in aBST $7 \mathrm{~d}$ before stress exposure. Tracer injections were aimed at the boundary between the dorsomedial and fusiform subdivisions of aBST (Fig. 1), and only animals that included appropriately centered tracer injections with minimal involvement of potentially confounding cell groups were included in the analyses.

After accurately placed injections of tracer in prefrontal and ventral hippocampal regions, reliable and consistent distribution 

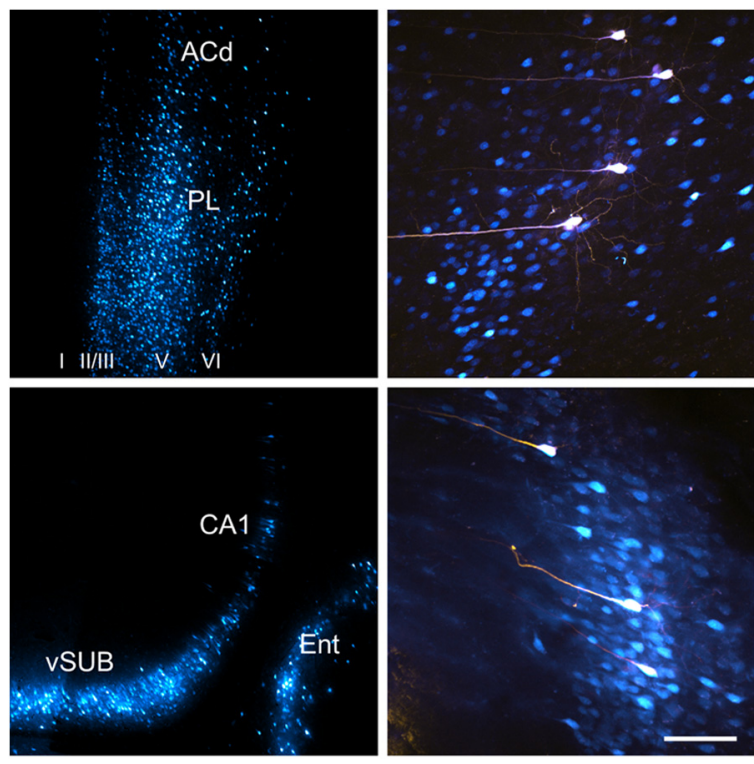

Figure 2. Digital images showing examples of retrograde labeling in PL (top row) and vSUB (bottom row). Left column, Examples of retrogradely labeled patterns after FB injections in aBST. Right column, Images approximating the actual level of magnification used $(40 \times)$ when injecting LY fluorescent dye into FB-labeled cell bodies (cyan). In these images, dyeimpregnated neurons (orange) were minimally filled to optimally illustrate colocalization of each label. Maximal loading with LY is necessary to perform the high-resolution imaging and spine analysis, but the resultant intensity of fluorescence would obscure visualization for illustrative purposes. CA1, Cornu ammoni of hippocampus; Ent, entorhinal cortex. Scale bar: top left, $500 \mu \mathrm{m}$; bottom left, $300 \mu \mathrm{m}$; right column, $100 \mu \mathrm{m}$.

of retrograde labeling was observed (Fig. 2). During the dyefilling procedure, laminae of interest were carefully discriminated from undesired adjacent-lying regions. For example, PL was differentiated from the dorsally adjacent anterior cingulate area (ACd) by an absence of retrogradely labeled neurons in ACd, because previous work had shown ACd to be void of any inputs into aBST and adjacent-lying structures. Several basic cytoarchitectonic differences between PL and the infralimbic area (IL) were used to prevent inadvertent cell filling. After tracer injections into aBST, PL displays a relative abundance of retrogradely labeled neurons, whereas an increasing gradient of labeled cells extends ventrally into IL. IL also lacks both the well-defined boundary distinguishing layer $2 / 3$ from layer 1 , as well as the adherence to clearly visible lamination patterns of dorsal- and rostral-lying cortical fields (i.e., layers $2 / 3$ and 5). In ventral hippocampus, vSUB is essentially a ventral extension of layer CA1 and is readily defined by the loss of a tightly packed principal cell layer into one that is broader and more dispersed. vSUB may be further differentiated from CA1 by a ventrally increasing gradient of retrogradely labeled neurons after tracer injections in aBST (Swanson and Cowan, 1977; Cullinan et al., 1993). Some sparse labeling of neurons was noted in CA1 after tracer injections in aBST, but inadvertent dye filling of these neurons was avoided because of their location sufficiently dorsal to the dense band of labeling that defined vSUB.

\section{Effects of CVS on structural plasticity in prefrontal neurons implicated in an HPA-inhibitory circuit}

Several forms of repeated/chronic stress and exogenous glucocorticoid (GC) administration are known to produce structural alterations throughout mPFC, decrements in neuronal excitability, and impairments in prefrontal-dependent behavioral tasks (Cerqueira et al., 2005a,b; Liston et al., 2006; Liu and Aghajanian,
2008; Dias-Ferreira et al., 2009; Hains et al., 2009). The distal aspects of apical dendrites are most susceptible to the effects of chronic stress and GCs, showing reduced dendritic length and branch number, decreased spine density, and altered spine morphology (Radley et al., 2006b, 2008; Liu and Aghajanian, 2008; Bloss et al., 2011), but no studies to date have linked this structural reorganization in $\mathrm{mPFC}$ to neural circuit alterations underlying function. In addition, stress-induced structural plasticity in mPFC is not likely ubiquitous, because several reports have shown experience-dependent cortical plasticity to be cell type dependent and circuit specific (Holtmaat et al., 2006; Shansky et al., 2009). Thus, our initial survey gauged the effects of CVS on dendritic morphology and spine density in a circuit of prefrontal neurons implicated in stress-induced HPA inhibition.

\section{Dendritic alterations}

Pyramidal neurons in PL were labeled after retrograde tracer injections into aBST, followed by either $14 \mathrm{~d}$ exposure to CVS or similar handling absent stress for controls. Analyses were performed on neurons that were retrogradely labeled or unlabeled and then filled with LY in CVS and control groups. One-way ANOVA revealed that $14 \mathrm{~d}$ CVS produced main effects for atrophy in apical dendritic arbors (length, $F_{(2,12)}=9.85, p<0.05$; number of branch endings, $\left.F_{(2,12)}=9.85, p<0.05\right)$, with post hoc comparisons showing significant stress-induced decreases in apical dendritic length of both aBST-projecting and unlabeled neurons by 30 and $28 \%$, respectively ( $p<0.05$ for each; Fig. 3, left). Similar effects on the total number of branch endings in apical dendrites were observed, with 31 and 22\% reductions in aBSTprojecting and unlabeled populations, respectively, after CVS compared with unstressed controls ( $p<0.05$; Fig. 3, left). Sholl analysis of apical dendrites showed the most prominent effects of CVS in the distal aspects of the arbor, both in aBST-projecting and unlabeled neurons (Fig. 3, left). One-way ANOVA performed at each radial distance revealed main effects at $250 \mu \mathrm{m}$ $\left(F_{(2,12)}=13.03, p<0.05\right), 300 \mu \mathrm{m}\left(F_{(2,12)}=6.83, p<0.05\right), 350$ $\mu \mathrm{m}\left(F_{(2,12)}=26.87, p<0.05\right)$, and $400 \mu \mathrm{m}\left(F_{(2,12)}=13.21, p<\right.$ $0.05)$. Similarly, post hoc pairwise comparisons showed significant reductions in CVS-treated relative to unstressed control animals at each of the radial distances in which main effects were present ( $p<0.05$ for each). However, when subpopulations of aBST-projecting and unlabeled PL neurons were compared as a function of chronic stress, no differences were observed. Furthermore, no effects of CVS were observed on PL basal dendrites as a function of either treatment or neuronal subpopulation (Fig. 3, left).

\section{Dendritic spine density and subtype}

Dendritic spines comprise sites of postsynaptic contact for the vast majority of excitatory input in cortical structures and represent the primary site of structural plasticity in pyramidal neurons (Nimchinsky et al., 2002; Holtmaat and Svoboda, 2009). Although the assessment of changes in dendritic spine density provides a reliable index for alterations in total excitatory synapse number within an anatomical region (Hao et al., 2003; Tang et al., 2004), spines also exhibit a high degree of morphological diversity, such that their classification into subtypes has predictive value for understanding synaptic function. The majority of spines are typified as thin, having a long and/or thin neck, and small thin head. A second subtype, termed mushroom spines, is characterized by a larger-diameter lobe-shaped head and small neck. A third subtype, stubby spines, lacks a neck and is shorter with a wide-head diameter (Peters and Kaiserman-Abramof, 1970; Harris and Stevens, 1989). Whereas thin and stubby spines represent 

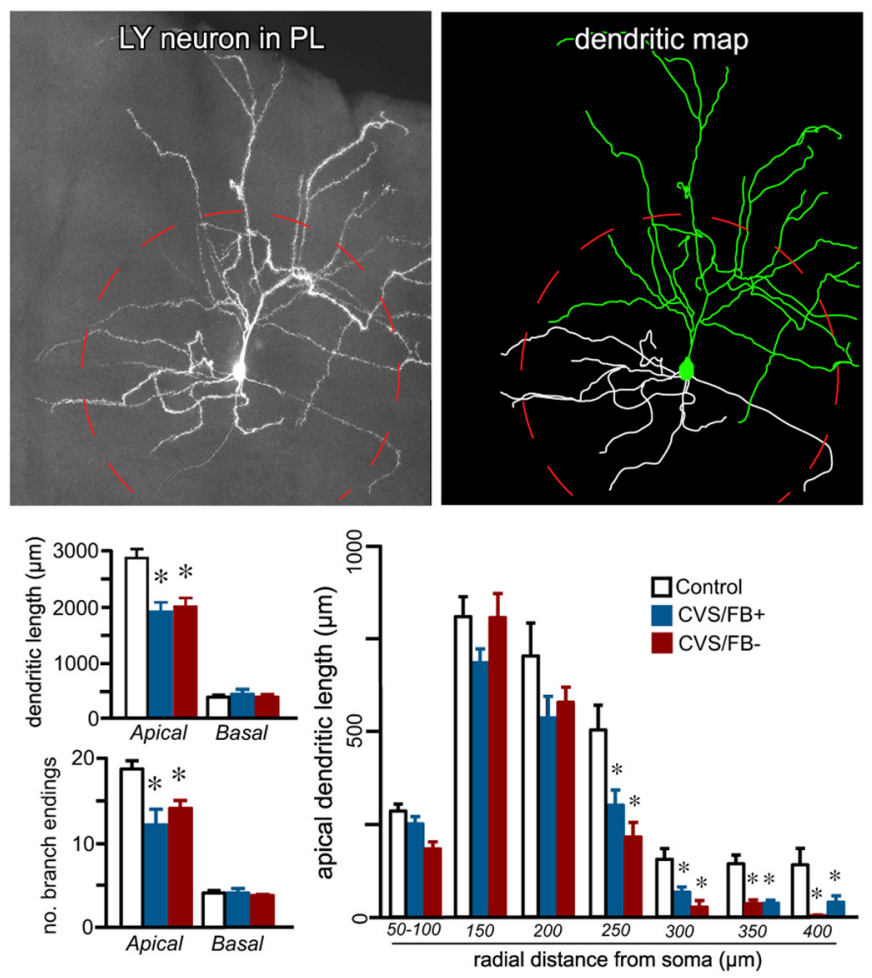
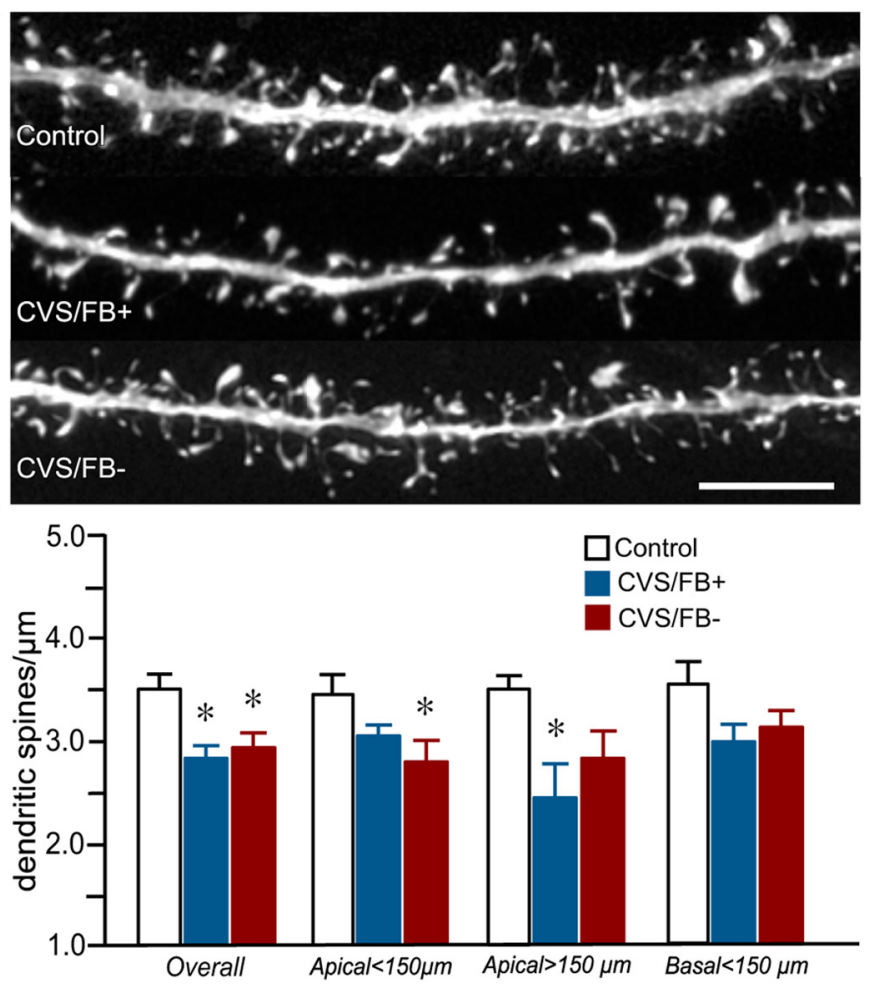

Figure 3. Top left, Example neuron in layer 2/3 of PL that was iontophoretically filled (left) and the rendering of its dendritic tree (middle) using computer-assisted morphometry. The apical dendritic tree points up toward the pial surface, whereas the axon and basal dendrites radiate from the opposite pole of the cell body. The red dashed circle demarcates the $150 \mu \mathrm{m}$ boundary used to partition the dendritic tree for spine analyses. Bottom left, Histograms for dendritic length and number of branch endings for apical and basal dendrites. CVS produced significant decreases in both dendritic indices, regardless of whether neurons were aBST-projecting $\left(\mathrm{FB}^{+}\right)$or unlabeled $\left(\mathrm{FB}^{-}\right)$. Preliminary analyses in control animals did not show any differences between aBST-projecting and non-projecting neurons and were pooled together into a single group (i.e., $\mathrm{FB}^{+/-}$). Bottom middle, The Sholl analysis for summed dendritic length as a function of radial distance shows that the effects of CVS were most pronounced in the distal apical dendritic tree. Data represent mean \pm SEM for each index and are based on overall animal averages (i.e., $n=5$ animals per group; $n=1$ arbor per neuron; $n=5$ neurons per animal). Top right, Examples of deconvolved confocal laser-scanning microscopy images of dendritic segments as a function of treatment status. Bottom right, CVS induced a significant, comparable degree of decreases in overall spine density in both subpopulations of LY-labeled PL neurons. * $p<0.05$, statistically significant differences from unstressed controls. Data represent mean \pm SEM for each index and are based on animal averages (i.e., $n=5$ animals per group; $n=1-3$ segments per neuron; $n=5$ neurons per animal). Scale bar: top left, middle images, $100 \mu \mathrm{m}$; three images in top right, $5 \mu \mathrm{m}$.

immature spine phenotypes that are more labile, mushroomshaped spines comprise more established, mature synapses that may persist for many weeks (Boyer et al., 1998; Matsuzaki et al., 2001, 2004; Kasai et al., 2003; Holtmaat et al., 2005; Petrak et al., 2005; Yasumatsu et al., 2008; Christoffel et al., 2011). Therefore, we classified dendritic spine density and morphometric features of high-resolution optical stacks of dendritic segments in LYfilled pyramidal neurons using NeuronStudio (Rodriguez et al., 2006; Radley et al., 2008). It has been shown that this method of analysis produces spine density values and morphometric indices very similar to EM analytic estimates and is not prone to population and classification sampling errors common to Golgi-based analytic approaches (Dumitriu et al., 2011, 2012). Dendritic arbors were imaged, and segments of the dendritic tree were analyzed over three ranges: (1) along both apical radial distances of $<150 \mu \mathrm{m}$ and (2) $>150 \mu \mathrm{m}$ from the cell body, and (3) along basal dendrites $<150 \mu \mathrm{m}$ from the cell body. These sampling ranges were informed by previous work showing that the effects of chronic stress on spine loss tended toward distal aspects of the apical dendrite (Radley et al., 2006b; Liu and Aghajanian, 2008; Bloss et al., 2011) and also provided a rationale for examining spine density data within these ranges separately from the overall pooled data. For this analysis, a total of $\sim 38,000$ dendritic spines were analyzed in PL.

One-way ANOVA showed that $14 \mathrm{~d}$ CVS produced main effects on dendritic spine density among all three ranges $\left(F_{(2,12)}=\right.$
5.88, $p<0.02$ ), with post hoc pairwise comparisons showing mean density reductions of $19 \%$ in aBST-projecting and $16 \%$ in unlabeled PL neurons (both $p<0.05$; Fig. 3, right). However, analysis of spine density within each individual range failed to reveal any main effect after CVS (apical $<150 \mu \mathrm{m}, F_{(2,12)}=4.05$, $p=0.052$; apical $>150 \mu \mathrm{m}, F_{(2,12)}=2.85, p=0.11$; basal $<150$ $\left.\mu \mathrm{m}, F_{(2,12)}=2.25, p=0.16\right)$. Nonetheless, pairwise comparisons showed significant reductions in distal apical spine density of aBST-projecting PL neuronal dendrites in CVS-treated compared with unstressed controls $(p<0.05)$, whereas unlabeled PL neurons showed significant decreases in proximal apical spine density in CVS relative to the unstressed group ( $p<0.05$; Fig. 3 , bottom right).

CVS revealed significant differences between aBST-projecting and unlabeled LY-filled dendritic spine subtypes, most notably within the subpopulation of mushroom-shaped spines. One-way ANOVA showed main effects in mushroom spine density for each category: (1) overall $\left(F_{(2,12)}=9.66, p<0.05\right)$; (2) $>150 \mu \mathrm{m}$ apical $\left(F_{(2,12)}=13.75, p=0.05\right)$; and $(3)<150 \mu \mathrm{m}$ basal $\left(F_{(2,12)}=7.00, p<0.05\right)$. Post hoc analyses showed that CVS resulted in a selective 35 and $31 \%$ decrease in overall mushroom spine density on aBST-projecting PL neurons compared with unstressed controls and unlabeled neurons from the CVS group ( $p<0.05$ for each; Fig. 4, middle left). Regional analyses showed that CVS resulted in the most substantial losses of mushroom spines in distal apical dendrites. CVS generated a 29\% decrease in 

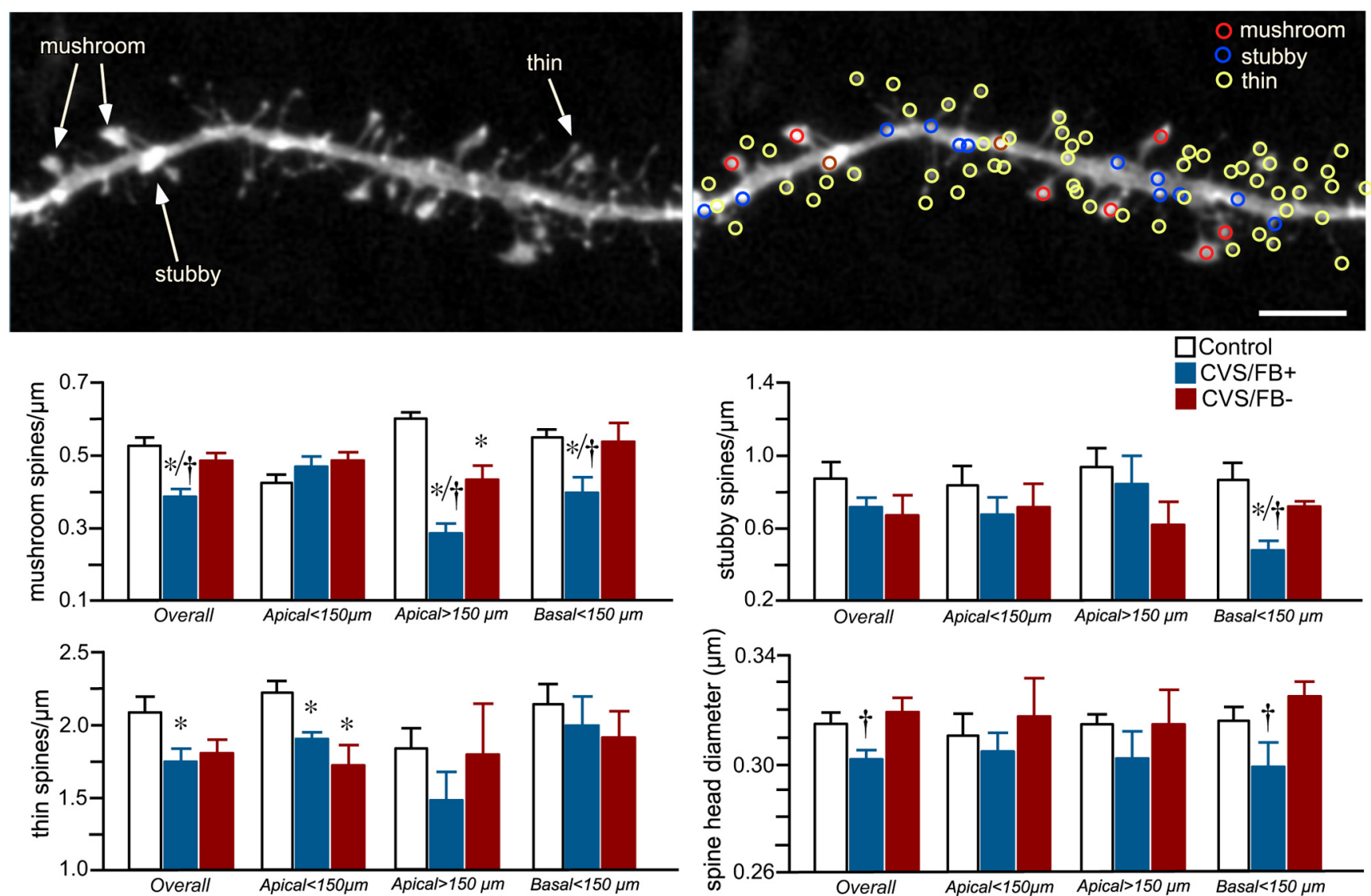

Figure 4. Top row, Example high-resolution deconvolved optical z-stack of a dendritic segment used for spine analysis with NeuronStudio software. Open colored circles designate spine subtypes based on user-defined parameters in the software (see Materials and Methods). Bottom panel, Histograms showing the effects of CVS on mushroom, stubby, and thin spine density and mean spine head diameter. (VS resulted in a significant decrease in overall, $>150$ apical, and $<150 \mu \mathrm{m}$ basal categories of mushroom spine density in aBST-projecting PL neurons ( $F B^{+}$) compared with unlabeled PL counterparts $\left(\mathrm{FB}^{-}\right)$and unstressed controls. Significant decreases in stubby spine densities were also evident in basal dendrites in $\mathrm{FB}^{+}$cells compared with $\mathrm{FB}^{-}$cells in the $\mathrm{CVS}^{-}$and unstressed control group. ${ }^{*} p<0.05$, differs significantly from unstressed controls; ${ }^{\dagger} p<0.05$, differs significantly from unlabeled neurons in CVS-treated animals. Data are represented as mean \pm SEM and based on animal averages for each index (i.e., $n=5$ animals per group; $n=1-3$ segments per neuron; $n=5$ neurons per animal). Scale bar, $5 \mu \mathrm{m}$ (applies to both images).

mushroom spine density at apical distances $>150 \mu \mathrm{m}$ in the unlabeled neuronal population as compared with unstressed animals $(p<0.05)$, whereas aBST-projecting neurons showed decreases of 33 and $51 \%$ compared with their unlabeled counterparts and control animals, respectively ( $p<0.05$ for each). CVS also produced a $28 \%$ reduction in the density of mushroom spines on proximal basal dendrites in aBST-projecting neurons compared with both unlabeled counterparts and unstressed control animals ( $p<0.05$ for each). A main effect of stubby spine density was also observed but only in basal dendrites (basal $<150$ $\left.\mu \mathrm{m}, F_{(2,12)}=5.60, p<0.05\right)$, whereby CVS produced, respectively, 40 and $47 \%$ decrements in aBST-projecting neurons compared with nonretrogradely labeled neurons in the same treatment group and unstressed control animals $(p<0.05$ for each; Fig. 4, middle right).

Examination of thin spine densities revealed main effects only within proximal apical dendrites (apical $<150 \mu \mathrm{m}, F_{(2,12)}=7.09$, $p<0.05$ ), with CVS resulting in, respectively, 17 and $26 \%$ decreases in aBST-projecting and nonretrogradely labeled neurons in PL compared with unstressed controls ( $p<0.05$ for each; Fig. 4 , bottom left). Pairwise comparisons at other dendritic intervals revealed decreases in thin spine density between aBST-projecting neurons in CVS relative to unstressed animals $(p<0.05)$, but these values did not differ significantly from unlabeled CVS counterparts $(p=0.71)$. Finally, group differences were analyzed for mean spine head diameter (Fig. 4, bottom right). Although one-way ANOVA failed to reveal a significant main effect $\left(F_{(2,12)}=3.24, p=0.082\right)$, aBST-projecting labeled neurons in the CVS group did show selective decreases in overall and proximal basal dendrites compared with unstressed control animals $(p<0.05)$.

These data corroborate previous reports of widespread structural plasticity in mPFC after chronic stress exposure and highlight a specific form of plasticity within the contingent of neurons in PL that issue projections to aBST. This pathway showed a profound and selective loss of mushroom spines after chronic stress, which is suggestive of synaptic destabilization in this circuit.

\section{Absence of structural plasticity in vSUB after CVS}

Previous studies have identified vSUB as the principal source of HPA-inhibitory extrinsic projections from the HF (Herman et al., 1992, 1995b), whereas evidence supports a link between GC hypersecretion and chronic stress-induced structural and functional alterations in the dorsal hippocampus (Sapolsky et al., 1986; Woolley et al., 1990; McEwen and Magarinos, 1997; McEwen, 2001). Recent functional evidence shows that aBST is a neural hub capable of integrating HPA-inhibitory signals from both prefrontal and hippocampal regions under acute stress conditions (Radley and Sawchenko, 2011). Nonetheless, whether neuroplasticity in ventral hippocampus contributes to chronic stress-induced alterations in HPA function remains to be ex- 

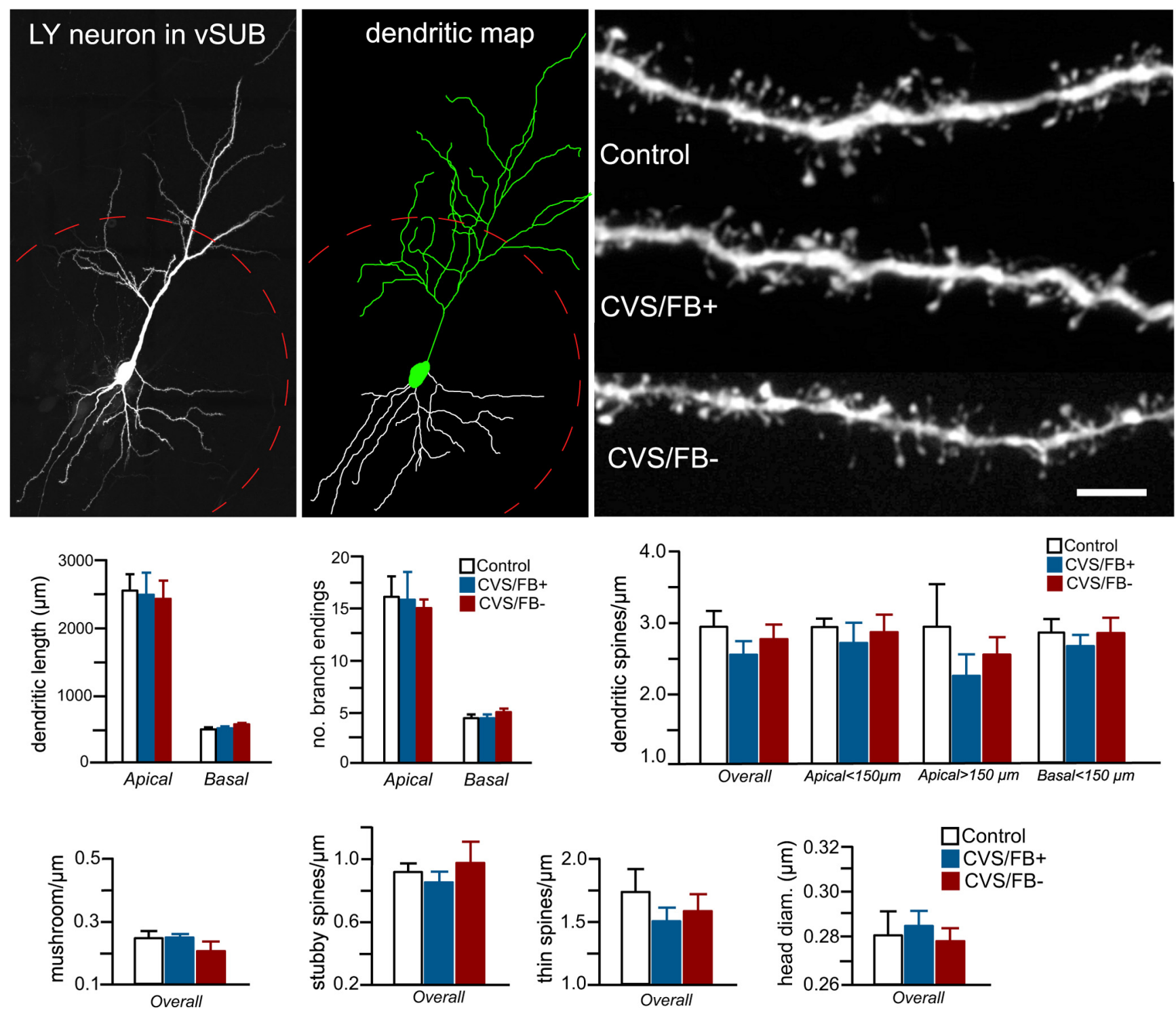

Figure 5. Top left, Example iontophoretically filled pyramidal neuron in vSUB (left) and the rendering of its dendritic tree (right) using computer-assisted morphometry. The apical dendritic tree is pointing upward and extends into the molecular layer, whereas the axon and basal dendrites radiate from the opposite pole of the cell body. The red dashed circle demarcates the $150 \mu \mathrm{m}$ boundary used to partition the dendritic tree for spine analyses. Top right, Examples of deconvolved confocal laser-scanning microscopy images of dendritic segments from vSUB neurons as a function of treatment status. Neurons in vSUB appear to be insensitive to the effects of CVS, because no differences were found in any of the structural indices examined in the treatment groups (middle and bottom rows). Data are represented as mean \pm SEM and are based on animal averages for each index (i.e., $n=5$ animals per group; $n=1-3$ segments per neuron; $n=5$ neurons per animal). Scale bar: top left, middle images, $50 \mu \mathrm{m}$; three images in top right, $5 \mu \mathrm{m}$.

amined. Therefore, we expanded our morphometric analyses to aBST-projecting and unlabeled pyramidal neurons in VSUB to test the generality of CVS-induced neuroplasticity in other upstream regions known to be important in HPA axis inhibition. Pyramidal neurons in vSUB were analyzed in the same groups of animals on which PL analysis had been performed, after FB injections into aBST and $14 \mathrm{~d}$ CVS. Retrogradely labeled and unlabeled neurons were filled with LY in CVS and control groups for imaging and morphometric analyses of dendrites. In contrast to the effects of CVS on structural plasticity in PL, no main effects were observed for either dendritic length (apical, $F_{(2,12)}=0.41, p=0.67$; basal, $F_{(2,12)}=0.05, p=$ 0.95 ) or number of branch endings (apical, $F_{(2,12)}=0.51$, $p=0.61$; basal, $\left.F_{(2,12)}=0.06, p=0.94\right)$ in vSUB pyramidal neurons (Fig. 5, left). Sholl analyses examining changes in dendritic length as a function of radial distances from the neuronal cell body also failed to uncover any alterations at any intervals within the dendritic tree as a function of stress or labeling status (data not shown).

Dendritic spine density and subtype were analyzed in aBSTprojecting and unlabeled vSUB pyramidal neurons in CVS and control groups. In these studies, $\sim 25,000$ spines were quantified as a function of dendritic length for each range (proximal apical, $<150 \mu \mathrm{m}$; distal apical, >150 $\mu \mathrm{m}$; proximal basal, $<150 \mu \mathrm{m}$ ) and then classified into spine subtypes for assessment of density as a function of treatment status. No main effects were observed for overall spine density $\left(F_{(2,12)}=0.37, p=0.70\right.$; Fig. 5 , right column), whereas post hoc pairwise comparisons failed to reveal any differences within any of the categories analyzed. Spine subtype examination also failed to reveal any main effects for overall density values (mushroom, $F_{(2,12)}=0.22, p=0.81$; stubby, $F_{(2,12)}=0.22, p=0.81$; thin, $F_{(2,12)}=0.09, p=0.92$; head 
diameter, $F_{(2,12)}=0.54, p=0.61$; Fig. 5, bottom row) or within any of the individual categories (data not shown).

Collectively, these analyses demonstrate a lack of sensitivity of pyramidal neurons in vSUB to the effects of chronic stress and raise doubts as to whether structural alterations in this hippocampal region account for modifications in HPA axis functioning after CVS. Nevertheless, CA3c neurons in dorsal hippocampus have been widely documented to undergo reliable changes in apical dendritic morphology under a range of repeated stress conditions (Watanabe et al., 1992; Magariños and McEwen, 1995; Sousa et al., 2000). Therefore, to provide a positive control for our analyses in vSUB, we undertook an ancillary experiment to verify these effects after $14 \mathrm{~d}$ of CVS. Lamination patterns in dentate gyrus and CA3c were identified by briefly treating sections with a fluorescent counterstain (DAPI), and CA3c neurons were then selected for LY dye injections in CVS and unstressed control animals. Consistent with previous reports (Watanabe et al., 1992; Magariños and McEwen, 1995), CVS resulted in an $18 \%$ decrease in apical dendritic length (control, $2123 \pm 154 \mu \mathrm{m}$; CVS, $\left.1751 \pm 107 \mu \mathrm{m} ; t_{(8)}=2.31, p=0.05\right)$ and a $20 \%$ decrease in the number of branch endings (control, $15.0 \pm$ 1.0 ; CVS, $\left.12.0 \pm 0.9 ; t_{(8)}=2.41, p<0.05\right)$, whereas no effects were evident in either index for basal dendrites (length: control, $713 \pm 47 \mu \mathrm{m}$; CVS, $671 \pm 73 \mu \mathrm{m} ; t_{(8)}=0.47, p=0.65$; branch endings: control, $5.3 \pm 0.3$; CVS, $\left.4.8 \pm 0.5 ; t_{(8)}=0.66, p=0.53\right)$.

\section{Diminution of functional activation in aBST-projecting PL neurons after CVS}

Our previous work has shown that aBST GABAergic neurons form a disynaptic circuit interceding for prefrontal and hippocampal inhibitory influences on acute stress-induced HPA activation (Radley et al., 2009; Radley and Sawchenko, 2011). A key feature of this system is that activation in these pathways in response to acute stress is linked to the inhibition of HPA output, raising the possibility that dampened activity in $\mathrm{PL}$ and/or vSUB may help to define a mechanism by which the HPA axis becomes overactivated after CVS. Moreover, because aBST-projecting PL neurons show structural alterations indicating the destabilization of excitatory synaptic input into this pathway after CVS exposure, we asked whether this would be paralleled by decreases in functional decreases in circuit activation.

To explore this issue, separate groups of animals received discrete pressure injections of FB in aBST, followed by exposure to $14 \mathrm{~d}$ of CVS. After the final day of CVS, these and previously unstressed rats were subjected for the first time to $30 \mathrm{~min}$ restraint and perfused $2 \mathrm{~h}$ later to assay restraint stress-induced engagement of aBST-projecting and unlabeled neurons in PL and vSUB using a dual immunolocalization labeling procedure for Fos protein and retrogradely labeled neurons. Two hours after restraint is a time point at which Fos protein levels are maximally elevated and is also sufficient for observing increases in central indices of HPA activation (Viau and Sawchenko, 2002). A third group of animals did not receive any stress exposure and was included to compare treatment effects to baseline Fos and CRF mRNA levels. Hybridization histochemistry for CRF mRNA expression in PVH was used to provide a central measure of HPA activation $\left(F_{(2,10)}=22.80, p<0.05\right)$. Post hoc pairwise comparisons revealed enhanced PVH CRF mRNA expression in both restraint challenged groups relative to unstressed controls (acute, by $28 \%$; CVS, by $52 \%$; both $p<0.05$ ), whereas an additional enhancement of transcript levels indicative of HPA axis sensitization (by 20\%) was seen after CVS treatment compared with the acute stress group ( $p<0.05$; Fig. 6, top).
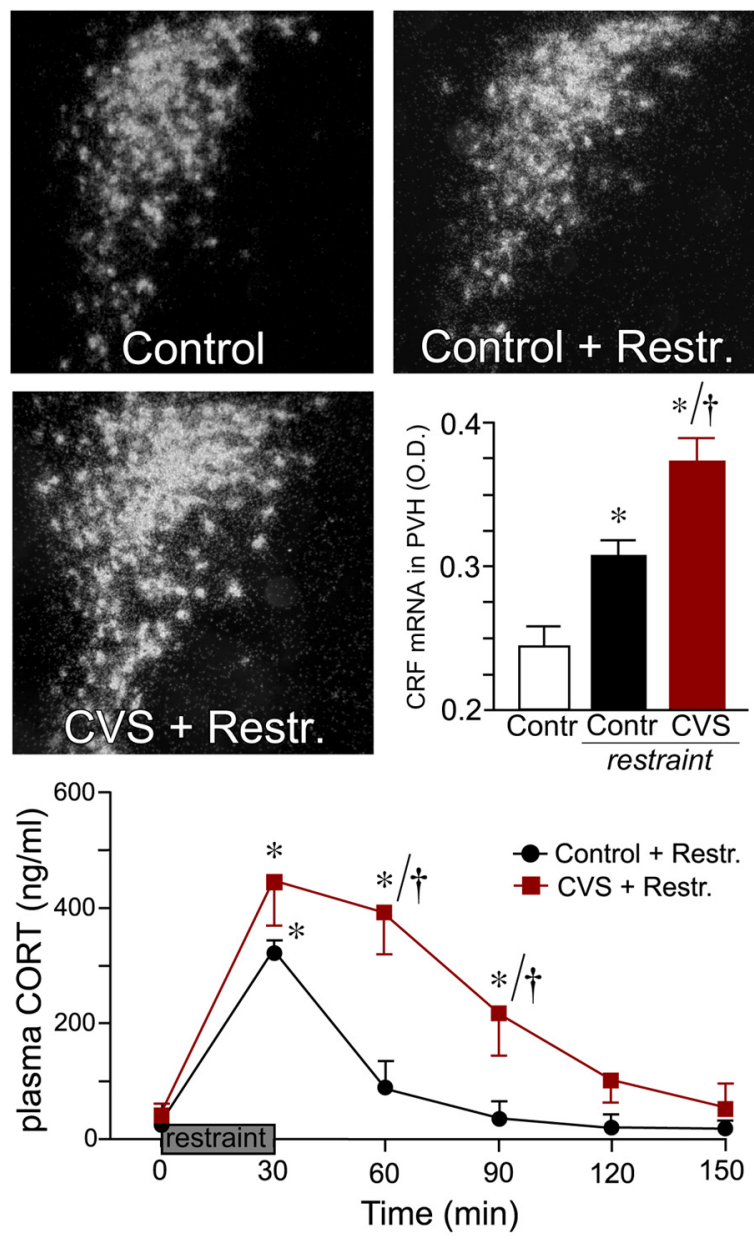

Figure 6. Dark-field photomicrographs (top) show representative examples of CRF mRNA expression in PVH as a function of treatment status. Middle right, Histogram showing mean $\pm S E M$ for relative levels of CRF mRNA expression in treatment groups. Restraint led to increases in CRF mRNA expression in PVH after 30 min restraint stress compared with unstressed control animals, whereas this effect was further enhanced after CVS exposure. ${ }^{*} p<0.05$, differs significantly from the unstressed control group; ${ }^{\dagger} p<0.05$, differs significantly from the acute stress group. $n=4-5$ per group. Bottom row, Mean \pm SEM plasma corticosterone (CORT) levels in control and CVS groups before ( $0 \mathrm{~min}$ ) and at 30 min intervals after exposure to restraint (Restr.). Whereas stress significantly increased levels of plasma CORT in both treatment groups, CVS animals showed prolonged increases at 60 and 90 min based on within-group comparison with pre-stress levels and between-group measures at each of these time points ( $p<0.05$ for each). ${ }^{*} p<0.05$, differs significantly from basal ( 0 min) values within each group; ${ }^{\dagger} p<0.05$, differs significantly from acutely restrained animals. $n=6$ per group.

Adrenocortical secretory responses before and after $30 \mathrm{~min}$ of restraint stress were also compared between separate groups of CVS and acute stress-treated animals on day 15 (Fig. 6, bottom). For this experiment, indwelling jugular catheters were implanted on the afternoon of day 13 of CVS, after the completion of stressor exposure for that day. Repeated-measures ANOVA for corticosterone data showed main effects for between factors (stress treatment, $F_{(1,14)}=5.88, p<0.05$ ) and within factors (time, $\left.F_{(5,70)}=57.16, p<0.05\right)$ and also a significant interaction between these variables $\left(F_{(5,70)}=4.30, p<0.05\right)$. Post hoc comparisons showed that, whereas CVS did not result in any significant difference in peak levels of corticosterone immediately after the 30 min restraint $(p=0.23)$, levels of corticosterone remained elevated in the CVS compared with acute restraint groups at 60 and 90 min time points (both $p<0.05$; Fig. 6). 

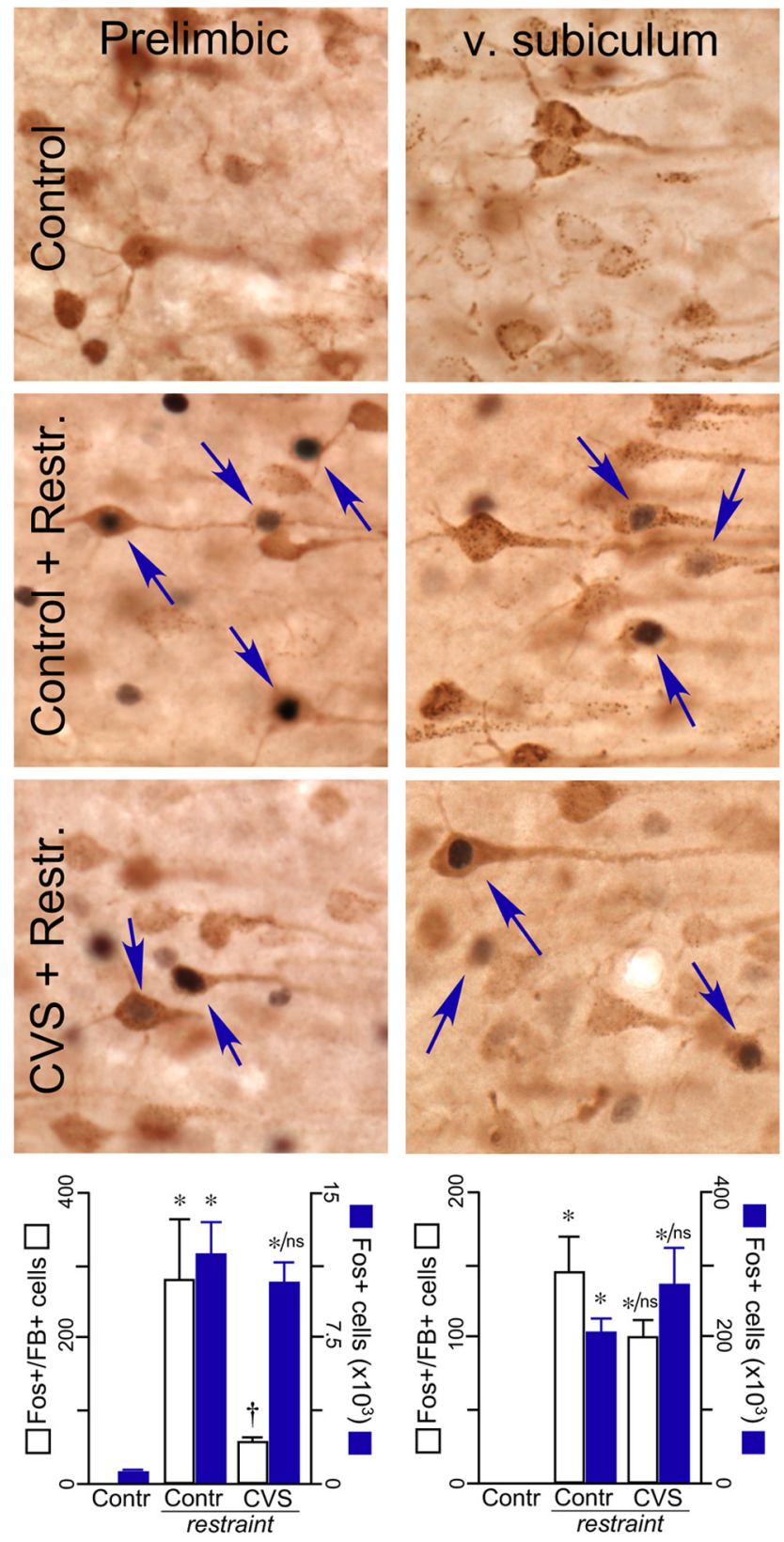

Figure 7. Photomicrographs show representative examples of dual immunoperoxidase staining of FB and Fos (arrows) at high magnification in treatment groups (rows) in PL and vSUB (columns). Thirty minutes of restraint increased overall levels of Fos expression and colocalization for Fos and tracer in PL and vSUB. CVS-treated animals showed a marked reduction in dual labeling for Fos and FB in PL compared with previously unstressed animals in response to the restraint challenge, whereas overall Fos levels remained elevated in this cortical subfield. In contrast, no significant decrements in either Fos plus FB or Fos were noted in vSUB as a function of CVS treatment. Bottom, Histograms showing mean \pm SEM for Fos plus FB (white bars) and Fos only (blue bars). Although PL showed decreases in dual colocalization for Fos and FB after CVS, Fos plus FB labeled cells in vSUB were not significantly different between acute and CVS groups. Contr, Control. ${ }^{*} p<0.05$, differs significantly from unstressed controls; ${ }^{\dagger} p<0.05$, differs significantly from the acute stress group. $n=4-5$ per group.

Exposure to $30 \mathrm{~min}$ of restraint stress also resulted in main effects for Fos activational responses in PL (aBST-projecting, $F_{(2,10)}=35.52, p<0.01$; unlabeled, $F_{(2,10)}=61.87, p<0.05$; Fig. 7, left column) and vSUB (aBST-projecting, $F_{(2,10)}=41.98, p<$ 0.01 ; unlabeled, $F_{(2,10)}=35.59, p<0.05$; Fig. 7 , right column), whereas no differences were noted in the number of retrogradely labeled neurons as a function of treatment group $\left(\mathrm{PL}, F_{(2,10)}=\right.$
$0.20, p=0.82$; vSUB, $\left.F_{(2,10)}=0.10, p=0.91\right)$. Although unstressed controls displayed levels of Fos expression that were nonexistent or negligible, acutely restrained animals manifested profound activation of Fos in PL and vSUB compared with their unstressed counterparts (both $p<0.05$ ). In the PL field, restraint-induced functional activation of unlabeled neurons persisted after CVS treatment $(p=0.26)$, whereas aBSTprojecting neurons showed a 75\% decrease in activation compared with the acutely restrained animals $(p<0.05$; Fig. 7 , bottom left). In contrast, the effects of CVS generally produced a downward trend in functional activation in vSUB, whereas neither subpopulation of vSUB neurons displayed a significant decrease in restraint-induced Fos expression after CVS treatment compared with the acutely stressed group $(p=0.11$ and $p=0.10$ for aBST-projecting and unlabeled neurons, respectively). Importantly, this experiment links decreased activation in aBSTprojecting PL neurons to elevated HPA output after CVS and suggests that the depletion of mature spine subtypes in the PL $\rightarrow$ aBST pathway may underlie its decreased functional engagement after CVS.

\section{Discussion}

By highlighting regressive structural and functional changes in aBST-projecting prefrontal cell groups during conditions of HPA axis hyperactivity that ensue from chronic stress, this study builds on our previous demonstration that aBST receives and integrates convergent input from $\mathrm{HF}$ and $\mathrm{mPFC}$ for the inhibitory control of acute emotional stress-induced HPA activity (Radley and Sawchenko, 2011). Whereas CVS produced reliable decrements in apical dendrites, spine density and subtype in all pyramidal PL neurons selected for fluorescent dye loading, pyramidal neurons in vSUB failed to show any decrements in dendritic or spine morphological indices after CVS. Anatomical tracing of convergent limbic cortical pathways to aBST revealed a differential vulnerability to the effects of chronic stress among PL neuronal subpopulations. Deficits in mushroom-shaped spines were observed in both apical and basal dendrites of aBST-projecting PL neurons after chronic stress exposure, whereas this spine subtype was spared in unlabeled PL neurons. Follow-up functional anatomical experiments linked decreased activation in aBST-projecting PL neurons to HPA sensitization after a novel restraint-stress challenge in animals previously subjected to the CVS regimen. Together, these experiments tie mushroom spine depletion to decreased functional activation in aBST-projecting PL neurons, defining a mechanism by which chronic stress-induced synapse loss in the PL $\rightarrow$ aBST pathway may dampen its ability to impart inhibitory control over the HPA axis, leading to overactivity of stress systems.

Here we have applied a high-throughput method for examining chronic-stress-induced dendritic spine plasticity in limbic cortical circuits implicated in an HPA-inhibitory network. NeuronStudio software enables the efficient 3D analysis of dendritic spine morphometric features from digitally reconstructed and deconvolved dendritic segments that were not previously afforded by other methodologies (Wearne et al., 2005; Rodriguez et al., 2006; Dumitriu et al., 2011). Dendritic spines are actin-rich protrusions representing junctional points of postsynaptic contact for the vast majority of excitatory input made into cortical pyramidal neurons, with alterations in shape and number providing a cellular correlate for learning and memory (Bailey and Kandel, 1993; Sorra and Harris, 2000; Kasai et al., 2003; Wilbrecht et al., 2010). Despite the heterogeneity of spine length, head/neck diameter, volume, and surface area, the classification of these features into broad categories is highly predictive of syn- 
aptic function. For instance, thin and stubby spines tend to be regarded as immature and may exhibit a higher turnover rate, whereas mushroom spines represent a more stable and mature population of excitatory synapses (Trachtenberg et al., 2002; Matsuzaki et al., 2004; Holtmaat et al., 2005; Yasumatsu et al., 2008).

It has been shown previously that chronic stress induces a net loss of excitatory synapses and significant alterations in spine geometry among PL neurons, particularly in the distal apical dendritic tree (Radley et al., 2006b; Michelsen et al., 2007; Liu and Aghajanian, 2008; Hains et al., 2009; Bloss et al., 2011). We previously used NeuronStudio software to characterize morphological changes in the dendritic spine population in PL neurons after 21 d of repeated restraint stress (Radley et al., 2008). Although the earlier configuration of this software did not classify dendritic spines into subtype, we reported significant downward shifts in spine surface area, volume, and length after chronic stress. In the present study, CVS produced selective decrements in large spine subtypes and in spine head diameters coinciding with these previously observed decreases in volume and surface area, notably in aBST-projecting neurons.

The principal finding from our morphometric analyses is that CVS resulted in the selective depletion of mature mushroom spines in aBST-projecting neurons in PL. This result provides a contrast with recent work suggesting that this subpopulation of spines remains stable across differing stress regimens and during aging (Bloss et al., 2011). To date, much of the data from the stress literature is derived from a regimen involving daily repeated exposure to restraint (Radley et al., 2006b, 2008; Liu and Aghajanian, 2008; Hains et al., 2009; Bloss et al., 2011), leading to the decline of HPA activation over successive presentations (Viau and Sawchenko, 2002). In contrast, CVS biases HPA responses toward enhanced activation over time (Willner, 1997), suggesting that stress-induced effects in mature spines are GC dependent. In support of this possibility, a recent report using twophoton microscopic in vivo imaging of spines in sensory cortical neurons found that prolonged GC exposure selectively increased the elimination of larger spines, particularly ones that were established earlier in life (Liston and Gan, 2011). Another report showed that GCs may destabilize the F-actin network selectively in large spines in hippocampus through a caldesmon-dependent mechanism (Tanokashira et al., 2012). Because we only analyzed a single time point after stress, our data do not address whether this morphological shift is attributable to the shrinkage or elimination of mushroom spines. Nevertheless, evidence supports the idea that mushroom spines in aBST-projecting PL neurons were selectively eliminated after CVS and point toward a GCdependent mechanism that warrants additional investigation.

Given that chronic stress produces more gross morphological effects on dendritic branching and spine density in aBSTprojecting PL neurons, the additional loss of mature spines in this subpopulation may appear at first glance nominal. However, functional anatomical experiments also unveiled a selective decrement in the restraint-induced engagement (Fos protein) in this pathway after CVS, whereas activation in other cell groups was unabated. Because we have extensively characterized the $\mathrm{vSUB} / \mathrm{PL} \rightarrow$ aBST $(\mathrm{GABA}) \rightarrow$ PVH pathway as an important inhibitory control over the HPA axis under acute stress conditions (Radley et al., 2009; Radley and Sawchenko, 2011), dampened activity in upstream components of this circuitry could readily account for HPA axis disinhibition (sensitization) during exposure to a novel restraint challenge after CVS. Based on these results, the loss of mature spines in the $\mathrm{PL} \rightarrow$ aBST pathway emerges as a key candidate mechanism accounting for decrements in functional activation, although additional experimentation is needed to address the necessity of this pathway in HPA sensitization. Nevertheless, consideration should be given to the fact that BST is widely implicated in anxiety (for review, see Davis et al., 1997) and that the chronic stress-induced disruption of PL $\rightarrow$ aBST pathway may also have broader consequences on behavior.

One important question raised by these results concerns which synaptic inputs are disrupted in aBST-projecting PL neurons that may account for the diminished activation of this pathway after CVS. The observed widespread reduction in mature spines in both apical and basal aspects of the dendritic tree is likely to disrupt both excitatory cortical/subcortical inputs into distal apical dendrites as well as local circuit excitation into basal dendrites (Nieuwenhuys, 1994; Douglas and Martin, 2004). The paraventricular nucleus of the thalamus (PVT) is important in this regard because it has been shown to play a critical role in restraining HPA responses under both conditions of habituation and facilitation (Bhatnagar and Dallman, 1998; Bhatnagar et al., 2002), and this thalamic region is extensively interconnected with PL (Heidbreder and Groenewegen, 2003). In our functional anatomical studies, we noted decreases in the restraint-induced engagement in PVT cell groups after CVS exposure (J.J.R., unpublished observations), although it is unknown whether these cells groups are anatomically linked to aBST-projecting neurons in PL. An intriguing possibility is that mature spine loss may lead to a decoupling of thalamic and prefrontal interactions, although additional work will be required to unravel these mechanisms.

To our knowledge, this is the first study to critically examine whether chronic stress is capable of inducing structural plasticity in ventral hippocampus. Our interest in extending the morphometric and functional examination to vSUB is derived from an extensive literature suggesting this region as the likely source of extrinsic projections from HF that impart stress-inhibitory influences over the HPA axis (Herman et al., 1995b; Herman and Mueller, 2006). However, our examination in vSUB failed to reveal any morphometric differences after CVS. Although analyses of restraint-induced Fos activation in vSUB were suggestive of a decreased sensitivity to restraint in aBST-projecting cell groups after CVS exposure, this trend was not significant (Fig. 7).

In contrast, stress-induced regressive structural plasticity in dorsal CA3c pyramidal neurons has been well documented (Watanabe et al., 1992; Magariños and McEwen, 1995; Magariños et al., 1997; Sousa et al., 2000; Sandi et al., 2003). Stress also decreases proliferation of neuronal precursors in the dentate gyrus, giving rise to overall reductions in granule cell number under repeated or chronic exposure (Gould et al., 1997, 1998; Pham et al., 2003). Recently, Snyder et al. (2011) showed that experimentally suppressing hippocampal neurogenesis led to the enhancement of HPA activation after acute and chronic stress exposure. Although these data all point toward dorsal hippocampus as a site of plasticity for chronic stress-related modifications in HPA functioning, additional work is required to clarify the involvement of vSUB circuitry in this regulation, whether via aBST or other relays in the basal forebrain.

\section{References}

Bailey CH, Kandel ER (1993) Structural changes accompanying memory storage. Annu Rev Physiol 55:397-426. CrossRef Medline

Bentivoglio M, Kuypers HG, Catsman-Berrevoets CE, Loewe H, Dann O (1980) Two new fluorescent retrograde neuronal tracers which are transported over long distances. Neurosci Lett 18:25-30. CrossRef Medline 
Bhatnagar S, Dallman M (1998) Neuroanatomical basis for facilitation of hypothalamic-pituitary-adrenal responses to a novel stressor after chronic stress. Neuroscience 84:1025-1039. CrossRef Medline

Bhatnagar S, Huber R, Nowak N, Trotter P (2002) Lesions of the posterior paraventricular thalamus block habituation of hypothalamic-pituitaryadrenal responses to repeated restraint. J Neuroendocrinol 14:403-410. CrossRef Medline

Bloss EB, Janssen WG, Ohm DT, Yuk FJ, Wadsworth S, Saardi KM, McEwen BS, Morrison JH (2011) Evidence for reduced experience-dependent dendritic spine plasticity in the aging prefrontal cortex. J Neurosci 31: 7831-7839. CrossRef Medline

Boyer C, Schikorski T, Stevens CF (1998) Comparison of hippocampal dendritic spines in culture and in brain. J Neurosci 18:5294-5300. Medline

Cerqueira JJ, Pêgo JM, Taipa R, Bessa JM, Almeida OF, Sousa N (2005a) Morphological correlates of corticosteroid-induced changes in prefrontal cortex-dependent behaviors. J Neurosci 25:7792-7800. CrossRef Medline

Cerqueira JJ, Catania C, Sotiropoulos I, Schubert M, Kalisch R, Almeida OF, Auer DP, Sousa N (2005b) Corticosteroid status influences the volume of the rat cingulate cortex-a magnetic resonance imaging study. J Psychiatr Res 39:451-460. CrossRef Medline

Chang HT, Kuo H, Whittaker JA, Cooper NG (1990) Light and electron microscopic analysis of projection neurons retrogradely labeled with Fluoro-Gold: notes on the application of antibodies to Fluoro-Gold. J Neurosci Methods 35:31-37. CrossRef Medline

Christoffel DJ, Golden SA, Dumitriu D, Robison AJ, Janssen WG, Ahn HF, Krishnan V, Reyes CM, Han MH, Ables JL, Eisch AJ, Dietz DM, Ferguson D, Neve RL, Greengard P, Kim Y, Morrison JH, Russo SJ (2011) I kinase regulates social defeat stress-induced synaptic and behavioral plasticity. J Neurosci 31:314-321. CrossRef Medline

Conrad CD (2008) Chronic stress-induced hippocampal vulnerability: the glucocorticoid vulnerability hypothesis. Rev Neurosci 19:395-411. Medline

Cullinan WE, Herman JP, Watson SJ (1993) Ventral subicular interaction with the hypothalamic paraventricular nucleus: evidence for a relay in the bed nucleus of the stria terminalis. J Comp Neurol 332:1-20. CrossRef Medline

Davis M, Walker DL, Lee Y (1997) Amygdala and bed nucleus of the stria terminalis: differential roles in fear and anxiety measured with the acoustic startle reflex. Philos Trans R Soc Lond B Biol Sci 352:1675-1687. CrossRef Medline

Dias-Ferreira E, Sousa JC, Melo I, Morgado P, Mesquita AR, Cerqueira JJ, Costa RM, Sousa N (2009) Chronic stress causes frontostriatal reorganization and affects decision-making. Science 325:621-625. CrossRef Medline

Diorio D, Viau V, Meaney MJ (1993) The role of the medial prefrontal cortex (cingulate gyrus) in the regulation of hypothalamic-pituitaryadrenal responses to stress. J Neurosci 13:3839-3847. Medline

Dong HW, Petrovich GD, Watts AG, Swanson LW (2001) Basic organization of projections from the oval and fusiform nuclei of the bed nuclei of the stria terminalis in adult rat brain. J Comp Neurol 436:430-455. CrossRef Medline

Dumitriu D, Rodriguez A, Morrison JH (2011) High-throughput, detailed, cell-specific neuroanatomy of dendritic spines using microinjection and confocal microscopy. Nat Protoc 6:1391-1411. CrossRef Medline

Dumitriu D, Laplant Q, Grossman YS, Dias C, Janssen WG, Russo SJ, Morrison JH, Nestler EJ (2012) Subregional, dendritic compartment, and spine subtype specificity in cocaine regulation of dendritic spines in the nucleus accumbens. J Neurosci 32:6957-6966. CrossRef Medline

Ericsson A, Kovács KJ, Sawchenko PE (1994) A functional anatomical analysis of central pathways subserving the effects of interleukin-1 on stressrelated neuroendocrine neurons. J Neurosci 14:897-913. Medline

Feldman S, Conforti N (1980) The role of the medial septal nucleus in mediating adrenocortical responses to somatosensory stimulation. J Neurosci Res 5:19-23. CrossRef Medline

Gould E, McEwen BS, Tanapat P, Galea LA, Fuchs E (1997) Neurogenesis in the dentate gyrus of the adult tree shrew is regulated by psychosocial stress and NMDA receptor activation. J Neurosci 17:2492-2498. Medline

Gould E, Tanapat P, McEwen BS, Flügge G, Fuchs E (1998) Proliferation of granule cell precursors in the dentate gyrus of adult monkeys is diminished by stress. Proc Natl Acad Sci U S A 95:3168-3171. CrossRef Medline

Grippo AJ, Moffitt JA, Johnson AK (2002) Cardiovascular alterations and autonomic imbalance in an experimental model of depression. Am J Physiol Regul Integr Comp Physiol 282:R1333-R1341. CrossRef Medline Grippo AJ, Beltz TG, Johnson AK (2003) Behavioral and cardiovascular changes in the chronic mild stress model of depression. Physiol Behav 78:703-710. CrossRef Medline

Hains AB, Vu MA, Maciejewski PK, van Dyck CH, Gottron M, Arnsten AF (2009) Inhibition of protein kinase $C$ signaling protects prefrontal cortex dendritic spines and cognition from the effects of chronic stress. Proc Natl Acad Sci U S A 106:17957-17962. CrossRef Medline

Hajszan T, Dow A, Warner-Schmidt JL, Szigeti-Buck K, Sallam NL, Parducz A, Leranth C, Duman RS (2009) Remodeling of hippocampal spine synapses in the rat learned helplessness model of depression. Biol Psychiatry 65:392-400. CrossRef Medline

Hao J, Janssen WG, Tang Y, Roberts JA, McKay H, Lasley B, Allen PB, Greengard P, Rapp PR, Kordower JH, Hof PR, Morrison JH (2003) Estrogen increases the number of spinophilin-immunoreactive spines in the hippocampus of young and aged female rhesus monkeys. J Comp Neurol 465:540-550. Medline

Harris KM, Stevens JK (1989) Dendritic spines of CA 1 pyramidal cells in the rat hippocampus: serial electron microscopy with reference to their biophysical characteristics. J Neurosci 9:2982-2997. Medline

Heidbreder CA, Groenewegen HJ (2003) The medial prefrontal cortex in the rat: evidence for a dorso-ventral distinction based upon functional and anatomical characteristics. Neurosci Biobehav Rev 27:555-579. CrossRef Medline

Herman JP, Mueller NK (2006) Role of the ventral subiculum in stress integration. Behav Brain Res 174:215-224. CrossRef Medline

Herman JP, Cullinan WE, Young EA, Akil H, Watson SJ (1992) Selective forebrain fiber tract lesions implicate ventral hippocampal structures in tonic regulation of paraventricular nucleus corticotropin-releasing hormone (CRH) and arginine vasopressin (AVP) mRNA expression. Brain Res 592:228-238. CrossRef Medline

Herman JP, Adams D, Prewitt C (1995a) Regulatory changes in neuroendocrine stress-integrative circuitry produced by a variable stress paradigm. Neuroendocrinology 61:180-190. CrossRef Medline

Herman JP, Cullinan WE, Morano MI, Akil H, Watson SJ (1995b) Contribution of the ventral subiculum to inhibitory regulation of the hypothalamopituitary-adrenocortical axis. J Neuroendocrinol 7:475-482. CrossRef Medline

Holtmaat A, Svoboda K (2009) Experience-dependent structural synaptic plasticity in the mammalian brain. Nat Rev Neurosci 10:647-658. CrossRef Medline

Holtmaat AJ, Trachtenberg JT, Wilbrecht L, Shepherd GM, Zhang X, Knott GW, Svoboda K (2005) Transient and persistent dendritic spines in the neocortex in vivo. Neuron 45:279-291. CrossRef Medline

Holtmaat A, Wilbrecht L, Knott GW, Welker E, Svoboda K (2006) Experience-dependent and cell-type-specific spine growth in the neocortex. Nature 441:979-983. CrossRef Medline

Jaferi A, Bhatnagar S (2006) Corticosterone can act at the posterior paraventricular thalamus to inhibit hypothalamic-pituitary-adrenal activity in animals that habituate to repeated stress. Endocrinology 147:4917-4930. CrossRef Medline

Kasai H, Matsuzaki M, Noguchi J, Yasumatsu N, Nakahara H (2003) Structure-stability-function relationships of dendritic spines. Trends Neurosci 26:360-368. CrossRef Medline

Krettek JE, Price JL (1977) The cortical projections of the mediodorsal nucleus and adjacent thalamic nuclei in the rat. J Comp Neurol 171:157-191. CrossRef Medline

Liston C, Gan WB (2011) Glucocorticoids are critical regulators of dendritic spine development and plasticity in vivo. Proc Natl Acad Sci U S A 108: 16074-16079. CrossRef Medline

Liston C, Miller MM, Goldwater DS, Radley JJ, Rocher AB, Hof PR, Morrison JH, McEwen BS (2006) Stress-induced alterations in prefrontal cortical dendritic morphology predict selective impairments in perceptual attentional set-shifting. J Neurosci 26:7870-7874. CrossRef Medline

Liu RJ, Aghajanian GK (2008) Stress blunts serotonin- and hypocretinevoked EPSCs in prefrontal cortex: role of corticosterone-mediated apical dendritic atrophy. Proc Natl Acad Sci U S A 105:359-364. CrossRef Medline

Magariños AM, McEwen BS (1995) Stress-induced atrophy of apical dendrites of hippocampal CA3c neurons: comparison of stressors. Neuroscience 69:83-88. CrossRef Medline 
Magariños AM, Verdugo JM, McEwen BS (1997) Chronic stress alters synaptic terminal structure in hippocampus. Proc Natl Acad Sci U S A 94: 14002-14008. CrossRef Medline

Matsuzaki M, Ellis-Davies GC, Nemoto T, Miyashita Y, Iino M, Kasai H (2001) Dendritic spine geometry is critical for AMPA receptor expression in hippocampal CA1 pyramidal neurons. Nat Neurosci 4:10861092. CrossRef Medline

Matsuzaki M, Honkura N, Ellis-Davies GC, Kasai H (2004) Structural basis of long-term potentiation in single dendritic spines. Nature 429:761-766. CrossRef Medline

McEwen BS (2001) Plasticity of the hippocampus: adaptation to chronic stress and allostatic load. Ann N Y Acad Sci 933:265-277. CrossRef Medline

McEwen BS, Magarinos AM (1997) Stress effects on morphology and function of the hippocampus. Ann N Y Acad Sci 821:271-284. CrossRef Medline

Michelsen KA, van den Hove DL, Schmitz C, Segers O, Prickaerts J, Steinbusch HW (2007) Prenatal stress and subsequent exposure to chronic mild stress influence dendritic spine density and morphology in the rat medial prefrontal cortex. BMC Neurosci 8:107. CrossRef Medline

Nimchinsky EA, Sabatini BL, Svoboda K (2002) Structure and function of dendritic spines. Annu Rev Physiol 64:313-353. CrossRef Medline

Ottenweller JE, Natelson BH, Pitman DL, Drastal SD (1989) Adrenocortical and behavioral responses to repeated stressors: toward an animal model of chronic stress and stress-related mental illness. Biol Psychiatry 26:829841. CrossRef Medline

Papp M, Willner P, Muscat R (1991) An animal model of anhedonia: attenuation of sucrose consumption and place preference conditioning by chronic unpredictable mild stress. Psychopharmacology (Berl) 104: 255-259. CrossRef Medline

Peters A, Kaiserman-Abramof IR (1970) The small pyramidal neuron of the rat cerebral cortex. The perikaryon, dendrites and spines. Am J Anat 127:321-355. CrossRef Medline

Petrak LJ, Harris KM, Kirov SA (2005) Synaptogenesis on mature hippocampal dendrites occurs via filopodia and immature spines during blocked synaptic transmission. J Comp Neurol 484:183-190. CrossRef Medline

Pham K, Nacher J, Hof PR, McEwen BS (2003) Repeated restraint stress suppresses neurogenesis and induces biphasic PSA-NCAM expression in the adult rat dentate gyrus. Eur J Neurosci 17:879-886. CrossRef Medline

Radley JJ, Sawchenko PE (2011) A common substrate for prefrontal and hippocampal inhibition of the neuroendocrine stress response. J Neurosci 31:9683-9695. CrossRef Medline

Radley JJ, Sisti HM, Hao J, Rocher AB, McCall T, Hof PR, McEwen BS, Morrison JH (2004) Chronic behavioral stress induces apical dendritic reorganization in pyramidal neurons of the medial prefrontal cortex. Neuroscience 125:1-6. CrossRef Medline

Radley JJ, Rocher AB, Janssen WG, Hof PR, McEwen BS, Morrison JH (2005) Reversibility of apical dendritic retraction in the rat medial prefrontal cortex following repeated stress. Exp Neurol 196:199-203. CrossRef Medline

Radley JJ, Arias CM, Sawchenko PE (2006a) Regional differentiation of the medial prefrontal cortex in regulating adaptive responses to acute emotional stress. J Neurosci 26:12967-12976. CrossRef Medline

Radley JJ, Rocher AB, Miller M, Janssen WG, Liston C, Hof PR, McEwen BS, Morrison JH (2006b) Repeated stress induces dendritic spine loss in the rat medial prefrontal cortex. Cereb Cortex 16:313-320. CrossRef Medline

Radley JJ, Rocher AB, Rodriguez A, Ehlenberger DB, Dammann M, McEwen BS, Morrison JH, Wearne SL, Hof PR (2008) Repeated stress alters dendritic spine morphology in the rat medial prefrontal cortex. J Comp Neurol 507:1141-1150. CrossRef Medline

Radley JJ, Gosselink KL, Sawchenko PE (2009) A discrete GABAergic relay mediates medial prefrontal cortical inhibition of the neuroendocrine stress response. J Neurosci 29:7330-7340. CrossRef Medline

Rodriguez A, Ehlenberger D, Kelliher K, Einstein M, Henderson SC, Morrison JH, Hof PR, Wearne SL (2003) Automated reconstruction of threedimensional neuronal morphology from laser scanning microscopy images. Methods 30:94-105. CrossRef Medline

Rodriguez A, Ehlenberger DB, Hof PR, Wearne SL (2006) Rayburst sampling, an algorithm for automated three-dimensional shape analysis from laser scanning microscopy images. Nat Protoc 1:2152-2161. CrossRef Medline
Sandi C, Davies HA, Cordero MI, Rodriguez JJ, Popov VI, Stewart MG (2003) Rapid reversal of stress induced loss of synapses in CA3 of rat hippocampus following water maze training. Eur J Neurosci 17:24472456. CrossRef Medline

Sapolsky RM, Krey LC, McEwen BS (1986) The neuroendocrinology of stress and aging: the glucocorticoid cascade hypothesis. Endocr Rev 7:284-301. CrossRef Medline

Sawchenko PE, Cunningham ET Jr, Mortrud MT, Pfeiffer SW, Gerfen CR (1990) Phaseolus vulgaris-leucoagglutanin (PHA-L) anterograde axonal transport technique. Methods Neurosci 3:247-260.

Shansky RM, Hamo C, Hof PR, McEwen BS, Morrison JH (2009) Stressinduced dendritic remodeling in the prefrontal cortex is circuit specific. Cereb Cortex 19:2479-2484. CrossRef Medline

Shu SY, Ju G, Fan LZ (1988) The glucose oxidase-DAB-nickel method in peroxidase histochemistry of the nervous system. Neurosci Lett 85: 169-171. CrossRef Medline

Simmons DM, Swanson LW, Arriza JL (1989) A complete protocol for in situ hybridization of messenger RNAs in brain and other tissues with radiolabeled single-stranded RNA probes. J Histotechnol 12:169-181. CrossRef

Snyder JS, Soumier A, Brewer M, Pickel J, Cameron HA (2011) Adult hippocampal neurogenesis buffers stress responses and depressive behaviour. Nature 476:458-461. CrossRef Medline

Sorra KE, Harris KM (2000) Overview on the structure, composition, function, development, and plasticity of hippocampal dendritic spines. Hippocampus 10:501-511. CrossRef Medline

Sousa N, Lukoyanov NV, Madeira MD, Almeida OF, Paula-Barbosa MM (2000) Reorganization of the morphology of hippocampal neurites and synapses after stress-induced damage correlates with behavioral improvement. Neuroscience 97:253-266. CrossRef Medline

Swanson LW, Cowan WM (1977) An autoradiographic study of the organization of the efferent connections of the hippocampal formation in the rat. J Comp Neurol 172:49-84. CrossRef Medline

Swanson LW, Kuypers HG (1980) The paraventricular nucleus of the hypothalamus: cytoarchitectonic subdivisions and organization of projections to the pituitary, dorsal vagal complex, and spinal cord as demonstrated by retrograde fluorescence double-labeling methods. J Comp Neurol 194: 555-570. CrossRef Medline

Tang Y, Janssen WG, Hao J, Roberts JA, McKay H, Lasley B, Allen PB, Greengard P, Rapp PR, Kordower JH, Hof PR, Morrison JH (2004) Estrogen replacement increases spinophilin-immunoreactive spine number in the prefrontal cortex of female rhesus monkeys. Cereb Cortex 14:215-223. CrossRef Medline

Tanokashira D, Morita T, Hayashi K, Mayanagi T, Fukumoto K, Kubota Y, Yamashita T, Sobue K (2012) Glucocorticoid suppresses dendritic spine development mediated by down-regulation of caldesmon expression. J Neurosci 32:14583-14591. CrossRef Medline

Trachtenberg JT, Chen BE, Knott GW, Feng G, Sanes JR, Welker E, Svoboda K (2002) Long-term in vivo imaging of experience-dependent synaptic plasticity in adult cortex. Nature 420:788-794. CrossRef Medline

Viau V, Sawchenko PE (2002) Hypophysiotropic neurons of the paraventricular nucleus respond in spatially, temporally, and phenotypically differentiated manners to acute vs. repeated restraint stress: rapid publication. J Comp Neurol 445:293-307. CrossRef Medline

Vogt BA, Peters A (1981) Form and distribution of neurons in rat cingulate cortex: areas 32, 24, and 29. J Comp Neurol 195:603-625. CrossRef Medline

Watanabe Y, Gould E, McEwen BS (1992) Stress induces atrophy of apical dendrites of hippocampal CA3 pyramidal neurons. Brain Res 588: 341-345. CrossRef Medline

Wearne SL, Rodriguez A, Ehlenberger DB, Rocher AB, Henderson SC, Hof PR (2005) New techniques for imaging, digitization and analysis of three-dimensional neural morphology on multiple scales. Neuroscience 136:661-680. CrossRef Medline

Wilbrecht L, Holtmaat A, Wright N, Fox K, Svoboda K (2010) Structural plasticity underlies experience-dependent functional plasticity of cortical circuits. J Neurosci 30:4927-4932. CrossRef Medline

Willner P (1997) Validity, reliability and utility of the chronic mild stress model of depression: a 10-year review and evaluation. Psychopharmacology (Berl) 134:319-329. CrossRef Medline

Woolley CS, Gould E, McEwen BS (1990) Exposure to excess glucocortico- 
ids alters dendritic morphology of adult hippocampal pyramidal neurons. Brain Res 531:225-231. CrossRef Medline

Yasumatsu N, Matsuzaki M, Miyazaki T, Noguchi J, Kasai H (2008) Princi- ples of long-term dynamics of dendritic spines. J Neurosci 28:1359213608. CrossRef Medline 